Published November 2016

In Jeff Heinz, Rob Goedemans and Harry van der Hulst (Ed.) Dimensions of Linguistic

Stress, pp. 263-290. Cambridge University Press

\title{
One or many? In search of the default stress in Greek
}

\author{
Anthi Revithiadou \\ Aristotle University of Thessaloniki, revith@lit.auth.gr
}

Angelos Lengeris

University of Kent, a.lengeris@kent.ac.uk

\section{Introduction}

In languages with unpredictable stress, commonly known as lexical stress systems, stress is not fixed on a particular syllable by rule but is a specified property of individual morphemes (e.g., stems and affixes). In the absence of a lexically specified stress, a language-specific default stress emerges which represents the predictable, phonologically determined aspect of the stress system. The issue of whether the phonological default shows wider distribution across and within morphological classes and is favored by native listeners in stress detection tasks remains fairly unexplored in the literature. ${ }^{1}$ This article examines whether speakers of Greek, a language with a three-way accentual contrast (antepenultimate, penultimate and ultimate stress), ${ }^{2}$ show a bias for a specific stress pattern and, if yes, whether this bias depends on morphological information. To this end, two perception experiments testing Greek listeners' detection of stress were performed using stimuli with neutralized acoustic cues.

The most prominent acoustic correlates of Greek stress are duration and amplitude (Arvaniti 2002, 2007) but we do not know what will happen when these cues are neutralized and hence are no longer available to the listener. Since adult speakers of a language with unpredictable stress are very sensitive in perceiving stress contrasts compared, for example, to speakers of purely phonological stress systems (cf. The Stress Deafness Hypothesis of Acquisition, Peperkamp \& Dupoux 2002; Dupoux \& Peperkamp 2002; Peperkamp 2004; Dupoux et al. 2008), it is reasonable to assume that in such cases Greek listeners will have difficulty identifying stress. Neutralizing the acoustic cues that signal stress therefore provides an ideal test bed for exploring listeners' stress bias when confronted with a stress detection task.

In addition, given that unpredictable stress is assumed to be primarily the result of lexical specification (Kiparsky 1982; Idsardi 1992; Halle \& Idsardi 1995; Halle 1997; Inkelas 1999; Alderete 1999; Revithiadou 1999; van der Hulst 1999, 2012 among others), it has been claimed that speakers of lexical stress systems have developed mechanisms for storing information about stress during language acquisition. As a result, stress assignment information is engraved in the metrical representations of words (or, most likely,

\footnotetext{
${ }^{1}$ Cross-linguistic experimental research on the nature of the default in lexical stress systems includes, among others, Nikolaeva (1971), Crosswhite et al. (2003), Fainleib (2008), Lavitskaya \& Kabak (2011a,b, 2013) for Russian and Fainleib (2008) for Hebrew.

${ }^{2}$ The stress patterns are abbreviated as APU, PU and U, respectively.
} 
morphological elements) in speakers' Mental Lexicon. If this information is deeply-rooted in the system, this may mean that lexically-specified (i.e., non-default) stress will override the default in stress detection tasks.

Alternatively, given that speakers' stress grammars may also encode lexical frequency information (see Zuraw 2000; Hayes \& Londe 2006 among others), lexical frequencies may also play a key role in shaping speakers' stress detection judgments by outranking both inherent and predictable stress patterns. If, for instance, a stress pattern is commonly attested in words belonging to a specific morphological class, when listeners are confronted with this class they may be inclined to decide in favor of the more frequently attested pattern in their language.

This study explores these issues by examining Greek listeners' stress detection using perceptual stimuli with neutralized acoustic cues. We specifically asked whether listeners show a bias for a specific stress pattern and, if yes, whether this bias is guided by the phonological default or by the directives of lexical frequencies in Greek. Stress detection was examined in two experiments with manipulated stimuli, one in which all syllables were stressed and one in which all syllables were unstressed.

In the remainder of this article we present the basics of Greek nominal stress and describe the methodology and the results of the two perception experiments. We interpret these results taking into consideration the stress patterns dictated by lexical frequency as these are reflected in a corpus of approximately 5000 (underived) nouns drawn from a Greek dictionary. We conclude by proposing ways to integrate our findings in a theoretical analysis of stress in the Greek nominal system.

\section{Stress in Greek nouns}

Greek is a lexical accent system with three permissible stress patterns due to an inviolable three-syllable window requirement:
a. APU pí⿴ikos 'monkey-NOM.SG'
masc in $-o s$
b. PU tsobános 'shepherd-NOM.SG'
c. U maragós 'carpenter-NOM.SG'
a. APU yítonas 'neighbor-NOM.SG'
masc in $-a s$
b. PU eónas
c. U vasiljás
'century-NOM.SG'
'king-NOM.SG'

(3)
a. APU yéfira
'bridge-NOM.SG'
b. PU elpíða
'hope-NOM.SG'
c. U ayorá
'market-NOM.SG'
fem in $-a$

Certain stress patterns are assumed to be lexically-inflicted (4b-c) (Revithiadou 1999), while one pattern, namely APU stress, is claimed to represent the phonological default (4a) (Malikouti-Drachman \& Drachman 1989; Ralli \& Touratzidis 1992; Revithiadou 1999, 2007; 
Burzio \& Tantalou 2007 among others). ${ }^{3}$ Interestingly, verbs show less accentual contrasts than nouns and exhibit largely APU stress (Revithiadou 1999).
a. /yiton-as/
accentless root
b. /eón-as/
accented root
c. $\quad /$ vasilj$^{\wedge}-\mathbf{a s} /^{4}$
post-accenting root

However, more recent research on stress assignment has shown that APU stress shows limited occurrence in reading tasks, especially compared to PU stress (Protopapas et al. 2006). APU stress is also found to be marginal in suffixless words such as acronyms (see Nikolou et al. 2012; Topintzi \& Kainada 2012). Experimental evidence so far is therefore inconclusive as to the unmarked nature of the phonological default.

Although phonological analyses of Greek stress address issues of inter-paradigmatic (e.g., yitonikós 'neighborly', yitonitsa 'little neighborhood') and intra-paradigmatic (yítonas 'neighbor-NOM.SG, yitónon 'neighborhood-GEN.PL') mobility of stress, the distribution of APU, PU and U across and within noun classes has been totally ignored. In addition, while morphological accounts acknowledge that stress is an integral part of the nominal paradigm and is associated with gender distinctions (Ralli 2002, 2003, 2005; Anastassiadis \& CheilaMarkopoulou 2003; Varlokosta 2011; Holton et al. 2012 among others), such accounts do not address the issue of how exactly these stress patterns are dispersed across and within morphological classes.

When looking into the grammar, most morphological classes (m-classes) exhibit all three stress possibilities, as shown in (5), but whether certain m-classes show a bias for a specific stress pattern remains an open question which we aim at answering in the following sections.

(5) Stress patterns in major m-classes

\begin{tabular}{|c|c|c|c|c|c|c|c|}
\hline stress & & \multicolumn{6}{|c|}{ m-classes } \\
\hline $\mathbf{A P U}$ & $-\mathrm{OS}$ & -0 & -as & $-a$ & $-i_{\mathrm{fem}}$ & $\varnothing^{5}$ & - -is $^{6}$ \\
\hline PU & $-\mathrm{os}$ & -0 & -as & $-a$ & $-i_{\text {fem }}$ & $-\mathrm{i}_{\text {neut }}$ & $\varnothing$ \\
\hline $\mathbf{U}$ & $-\mathrm{OS}$ & -0 & -as(?) & $-a$ & $-\mathrm{i}_{\mathrm{fem}}(?)$ & $-i_{\text {neut }}$ & $\varnothing$ \\
\hline
\end{tabular}

\footnotetext{
${ }^{3}$ The phonological default is an analysis-specific construct. According to various analyses of Russian stress, for instance, the default is initial (Halle 1973, 1997; Kiparsky \& Halle 1977; Melvold 1990) or even post-stem (Alderete 1999, 2001a,b).

${ }^{4}$ The symbol ' $\wedge$ ' indicates non-locally realized stress. At the left side of a morpheme it denotes pre-accentuation while at the right side of a morpheme it denotes post-accentuation.

${ }^{5}$ Neuter nouns in $-i$ with monosyllabic bases (e.g., peð $i$ 'child') are mostly stressed on the U while neuter nouns in $-i$ with di-/polysyllabic bases (e.g., karið i 'walnut') are mostly stressed on the PU, suggesting the application of a rule of accentual allomorphy.

${ }^{6}$ Complex nouns such as deverbal nouns in /-tis/ (e.g. fititís 'student', Jitis 'diver') and denominal nouns in /-iotis/ (e.g., stratiótis 'soldier') were excluded. It is an open question whether such nouns are always treated as complex by native listeners.
} 


\section{Method}

\subsection{Selection of perceptual stimuli}

Stimuli selection was based on a method developed in Revithiadou et al. (2012) for creating pseudowords (PsWs) for experimental tasks in Greek. In order to reliably measure the degree of a listener's familiarity with a PsW, Revithiadou et al. (2012) used the Clean Corpus, ${ }^{7}$ a medium-sized freely available online Greek corpus containing over 200.000 types (29.000.000 tokens) from newspapers and magazines that provides a set of quantitative measures for assessing word familiarity. Two variables were used that take into account the phonological representation of the listed words rather than their orthographical representation: (i) Logmean bigram token frequency and (ii) Logmean bigram type frequency, which focus on phonemes of tokens and types respectively. ${ }^{8}$ The variables in $(6 \mathrm{~b}$ i-ii) count the number of phonological neighbors (if we apply replacement or replacement, deletion, insertion and transposition, respectively). The variable in (6b iii) is a less strict measure of phonological distance that calculates the mean phonological distance of the $\mathrm{N}$ (typically 20) nearest items.

(6) a. Bigram frequencies (phonemes only): i. Logmean bigram token frequency; ii. Logmean bigram type frequency.

b. Neighborhoods and cohorts: i. N phonological neighbors (replace only); ii. N phonological neighbors (replace, delete, insert, transpose); iii. Phonological Levenshtein distance 20.

Since the Clean Corpus does not provide any information on the morphological category of the listed words (e.g., nouns, verbs, pronouns) which is vital for testing the perception of Greek stress due to its morphology-oriented nature (recall that nouns, for example, employ more accentual contrasts than verbs), Revithiadou et al. (2012) only used a noun-targeted version of the Clean Corpus (NClean Corpus) containing 13.324 (underived inflected) nouns.

The constructed PsWs had simple syllable structures containing two and three syllables: CV.CV(C), CV.CV.CV(C), CCV.CV(C), and CCV.CV.CV(C). The PsWs were inflected from the five most productive morphological classes in Greek (-os, $-o,-a s,-a$, and $-i)$. Steps 1-4 were followed:

STEP 1: All nouns from the NClean Corpus were categorized according to their size and syllable structure.

STEP 2: Mean values and SDs for bigram frequencies (phonemes only) and neighborhoods and cohorts were calculated for each noun category of NClean (e.g., for disyllabic CV.CVC nouns in $-o s$, $-a s$, disyllabic CCV.CV nouns in $-o,-a,-i$, trisyllabic CCV.CV.CV nouns in $-o,-a,-i$, and so on). The range was restricted from $-1 \mathrm{SD}$ to $+1 \mathrm{SD}$. For instance, in CV.CV nouns, the mean value of BGtokfreqPho was 1,001 and the SD was 0,866 . Thus, the range was set from 0,135 to 1,867 .

\footnotetext{
7 The Clean Corpus created by Protopapas and his colleagues is a component of the "ILSP Psycho-Linguistic Resource" (http://speech.ilsp.gr/iplr, cf. Protopapas et al. 2010). On the same webpage, the reader can find information regarding the calculation of the variables in (6). We relied on the stressless version of the corpus because, given the aims of our study, we wanted to avoid variables taking into consideration information on the position of stress in their calculations.

${ }^{8}$ Bigrams are pairs of adjacent items; in phonological representations bigrams refer to pairs of phonemes.
} 
STEP 3: Novel PsWs were constructed and tested by the NumTool (http://speech.ilsp.gr/iplr/NumTool.aspx, see Protopapas et al. 2010), which provided quantitative measures of the variables in question for each listed word string on the basis of the Clean Corpus.

STEP 4: Only PsWs that fell within the defined range for all variables (see STEP 2) were selected for the experiments.

\subsection{Manipulation of perceptual stimuli}

Using the above procedure, Revithiadou et al. (2012) selected 260 PsWs. For the purpose of the current study, we recorded a male speaker of Standard Greek reading the PsWs in the carrier sentence /sti meyáli léna milái/ ' speaks to the elderly Lena' (lit. 'To

elderly Lena speaks'). The PsWs were placed in post-focus position (the focus of the sentence was on /mejáli/ 'elderly') so that they would be deaccented, i.e., they would have a flat pitch contour (Baltazani \& Jun 1999).

Of those PsWs, 195 were acoustically manipulated so that (a) all syllables contained stressed vowels (Experiment 1) and (b) all syllables contained unstressed vowels (Experiment 2), and 65 served as fillers (i.e., PsWs that retained their original stress). There were 20 disyllabic $(2 \sigma)$ PsWs and 19 trisyllabic $(3 \sigma)$ PsWs in each of the 5 m-classes $((20+19)$ PsWs $\times 5$ m-classes $=195 \mathrm{PsWs}$ ). The fillers were also $2 \sigma$ and $3 \sigma \mathrm{PsWs}$ with (APU/)PU/U stress $(13 \mathrm{PsWs} \times 5 \mathrm{~m}$-classes $=65 \mathrm{PsWs})$. The size and the syllabic structure of the PsWs were generally simple so that they will not be perceived as derived/morphologically complex (see Appendix for a complete list of the PsWs used in the experiments).

The 195 PsWs in Experiment 1 were manipulated as follows: The Greek speaker read two (or three in the case of $3 \sigma$ PsWs) versions of each PsW, one with the stress on the $1^{\text {st }}$ syllable and one on the $2^{\text {nd }}$ syllable (and one with stress on the $3^{\text {rd }}$ syllable in $3 \sigma$ PsWs). The unstressed syllable of the first version was then replaced with the stressed syllable of the second version (this replacement was done twice in $3 \sigma$ PsWs). The new PsWs thus contained syllables with only full (i.e., non-reduced) stressed vowels. Syllables were then normalized to have the same duration and intensity contour (by averaging the duration and intensity of the two/three vowels and applying the average duration and intensity values to both/three vowels using Praat scripts (Boersma \& Weenink 2011). All syllables of the resulting PsWs therefore had the same quality, duration, and amplitude with pitch contour remaining flat across syllables.

The same manipulation procedure was followed in Experiment 2 but this time the new PsWs contained syllables with only unstressed (reduced) vowels. Figure 1 shows an example of the original PsW (/kleto/) with stress on the $1^{\text {st }}$ syllable, while Figures 2 and 3 show the manipulated version of the PsW with both syllables stressed and both syllables unstressed, respectively. 


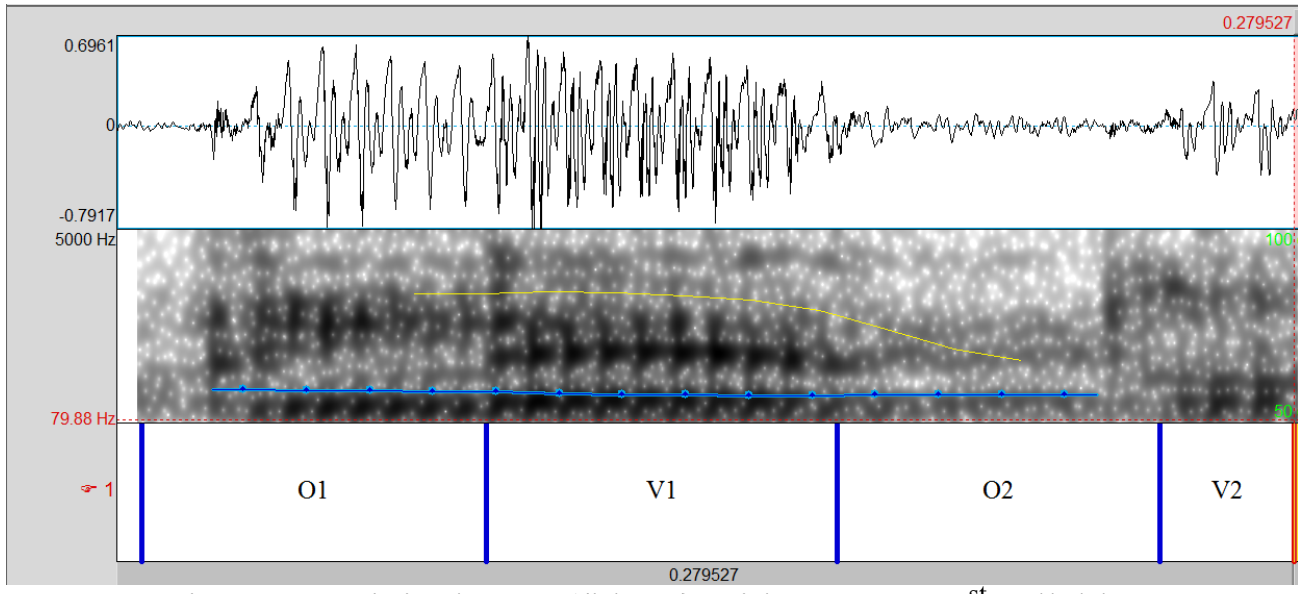

Figure 1: Original PsW (/kléto/) with stress on $1^{\text {st }}$ syllable.

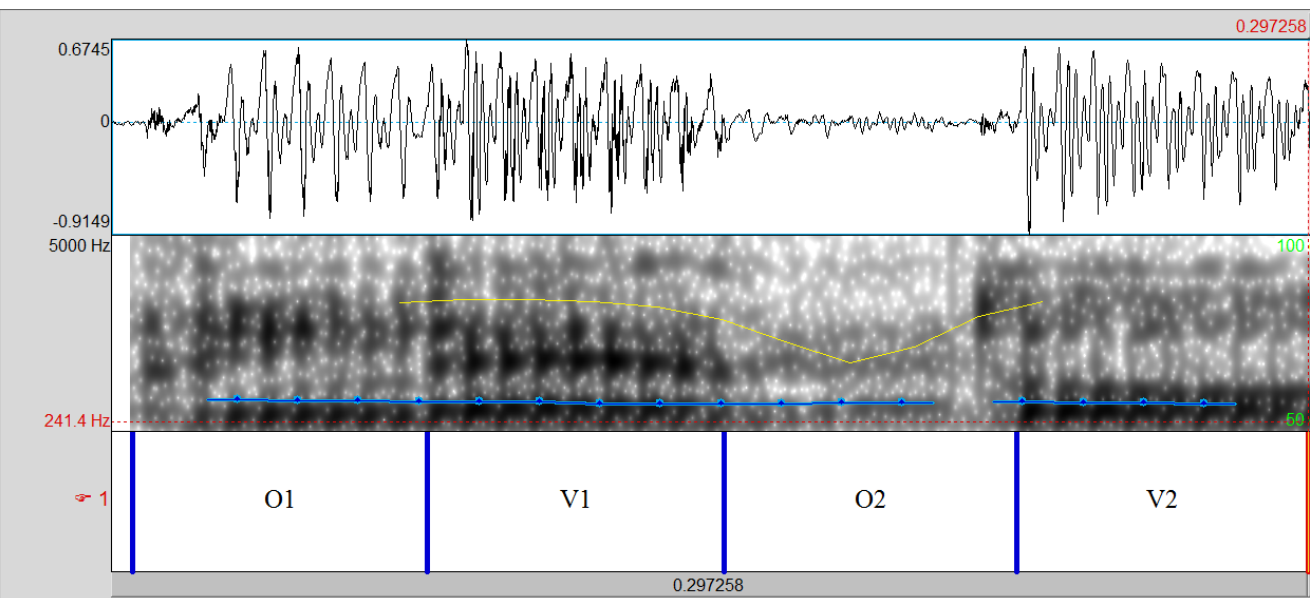

Figure 2: Manipulated PsW (/klétó/) used in Experiment 1 with both syllables stressed.

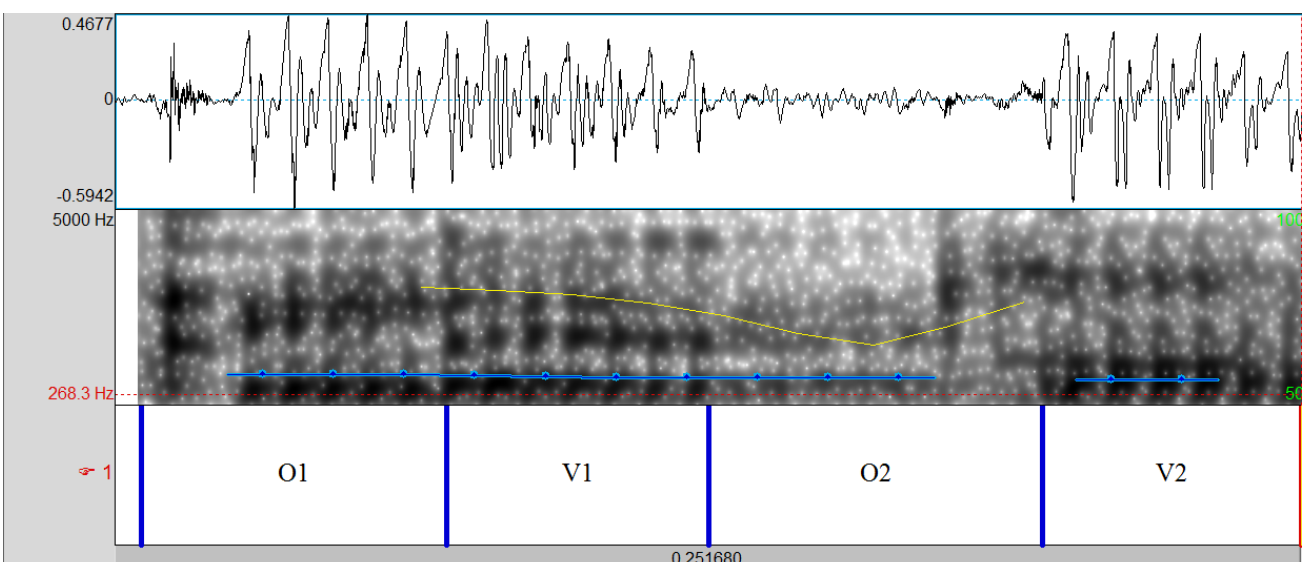

Figure 3: Manipulated PsW (/kleto/) used in Experiment 2 with both syllables unstressed. 


\subsection{Participants}

The participants were 26 native speakers of Greek ( 8 male, 18 female) with a mean age of 21 years old, all students at Aristotle University of Thessaloniki Department of Linguistics. The same speakers participated in both experiments.

\subsection{Procedure}

Participants were tested individually in a quiet room using a laptop computer and highquality headphones (AKG K81DJ). All participants were informed before the task that the words they were about to hear were nouns. They heard all 260 PsWs in random order and chose, by clicking on a label on the computer screen, between three (or four in $3 \sigma$ PsWs) options: "Stress on the first (syllable)", "Stress on the second (syllable)", "Stress on the third (syllable)", and "It is not clear where the stress falls" (lit. "In no syllable stress is perceptible."). Participants could hear each stimulus twice by clicking on a repeat button. A practice task with 20 PsWs preceded the experiment to familiarize participants with the procedure. There was an interval of 8 days between the two experiments. We collected 6760 answers in each experiment, for a total of 13520 answers.

\section{Results}

\subsection{The perception of (non-)prominence}

As shown in Figures 4 and 5, despite using stimuli with neutralized acoustic cues, the percentage of times Greek listeners erroneously detected prominence on one of two (or three) positions in Experiment 1 was significantly higher than the percentage of times they were not able to detect stress (coded as NA) in both $2 \sigma$ and $3 \sigma$ PsWs $\left(77 \%\right.$ vs. $23 \%, \chi^{2}(1)=723.485$, $\mathrm{p}=0.000$ and $75 \%$ vs. $25 \%, \chi^{2}(1)=616.783, p=0.000$ respectively).

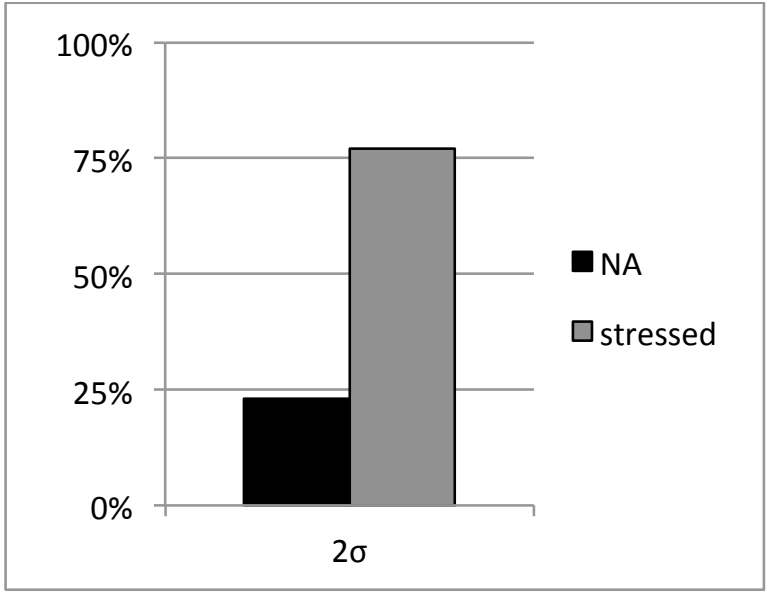

Figure 4: Percentage stress detection in $2 \sigma$ PsWs in Exp 1.

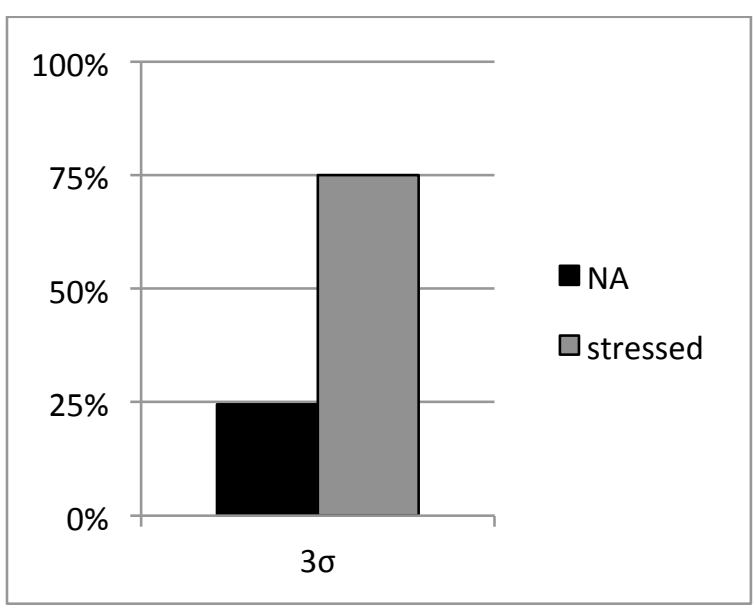

Figure 5: Percentage stress detection in $3 \sigma$ PsWs in Exp 1. 
These results were replicated in Experiment 2. As shown in Figures 6 and 7, the percentage of times Greek listeners erroneously detected prominence on a syllable was significantly higher than the percentage of times they could not detect prominence on any syllable in both $2 \sigma$ and $3 \sigma$ PsWs $\left(72 \%\right.$ vs. $28 \%, \chi^{2}(1)=491.835, p=0.000$ and $73 \%$ vs. $27 \%, \chi^{2}(1)=529.3$, $\mathrm{p}=0.000$ respectively).

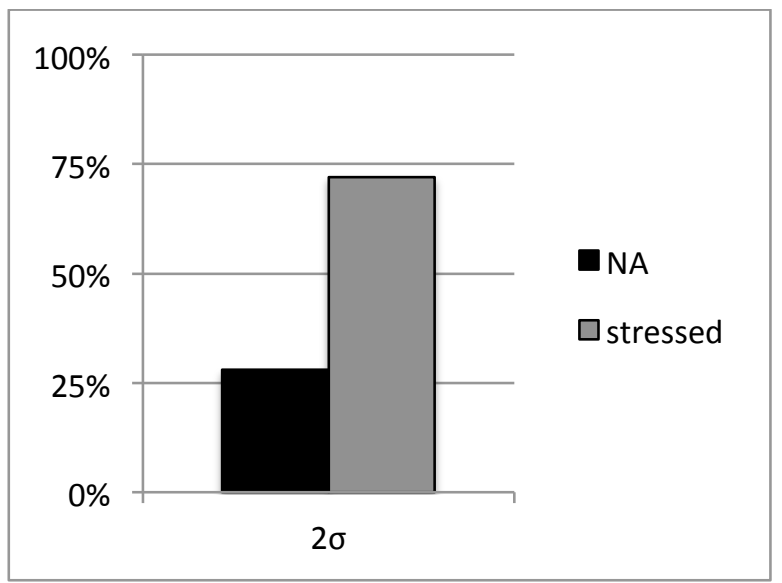

Figure 6: Percentage stress detection in $2 \sigma$ PsWs in Exp 2.

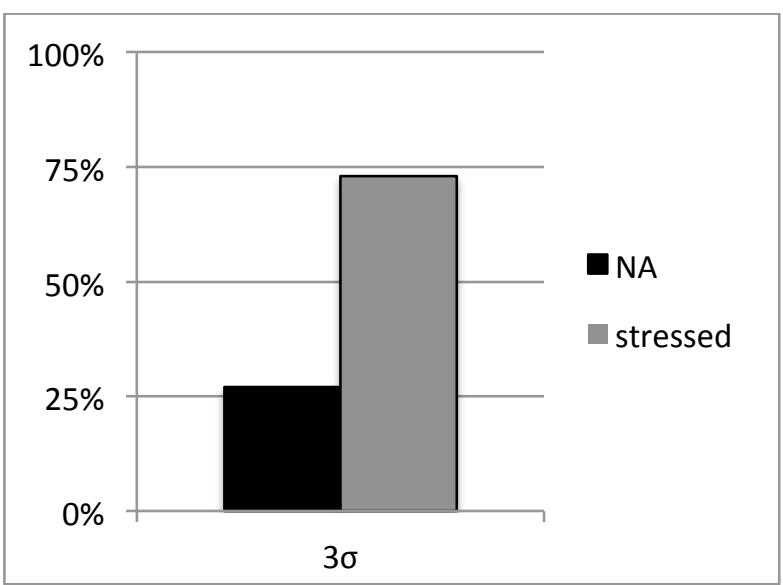

Figure 7: Exp 2 stress detection in $3 \sigma$ PsWs in Exp 2.

The results therefore showed that even when the acoustic cues that signal stress were no longer available to Greek listeners either because all syllables were equally stressed (Experiment 1) or equally unstressed (Experiment 2), they somehow still perceived prominence, revealing a bias towards stress detection. ${ }^{9}$ In the following sections we focus on those cases and explore whether Greek listeners are biased towards a specific stress pattern.

\subsection{Stress patterns across m-classes}

\subsubsection{Experiment 1}

When looking at stress detection patterns when listeners identified prominence in $2 \sigma$ words (Figure 8), it was found that PU stress was favored over U stress across morphological categories $^{10}\left(-a: \chi^{2}(1)=261.134, \mathrm{p}=0.000,-o: \chi^{2}(1)=9.818, \mathrm{p}=0.002,-\right.$ as: $\chi^{2}(1)=243.551$, $\left.\mathrm{p}=0.000,-o s: \chi^{2}(1)=58.247, \mathrm{p}=0.000\right)$.

\footnotetext{
${ }^{9}$ We leave further analysis of the 23-27\% range of NA answers together with that of fillers for the future. Regarding fillers, it is worth mentioning that not only there was a considerable percentage of NA responses but also there were cases where listeners' stress biases were strong enough to override the acoustic cues that signal Greek stress, biases which were analogous to the results obtained for the manipulated PsWs examined in this study. To give an example, $3 \sigma$ words stressed on the final syllable were mostly perceived as having APU stress if they belonged to the $-o$ and $-o s$ m-classes but as having PU or APU stress if they belonged to the $-a$ and $-a s$ m-classes.

${ }^{10}$ Because of space limitations, we report on the results of four m-classes: nouns in $-o s,-o,-a s$ and $-a$. Nouns in $-i$ were found to behave similarly to nouns in $-a$ and $-a s$.
} 

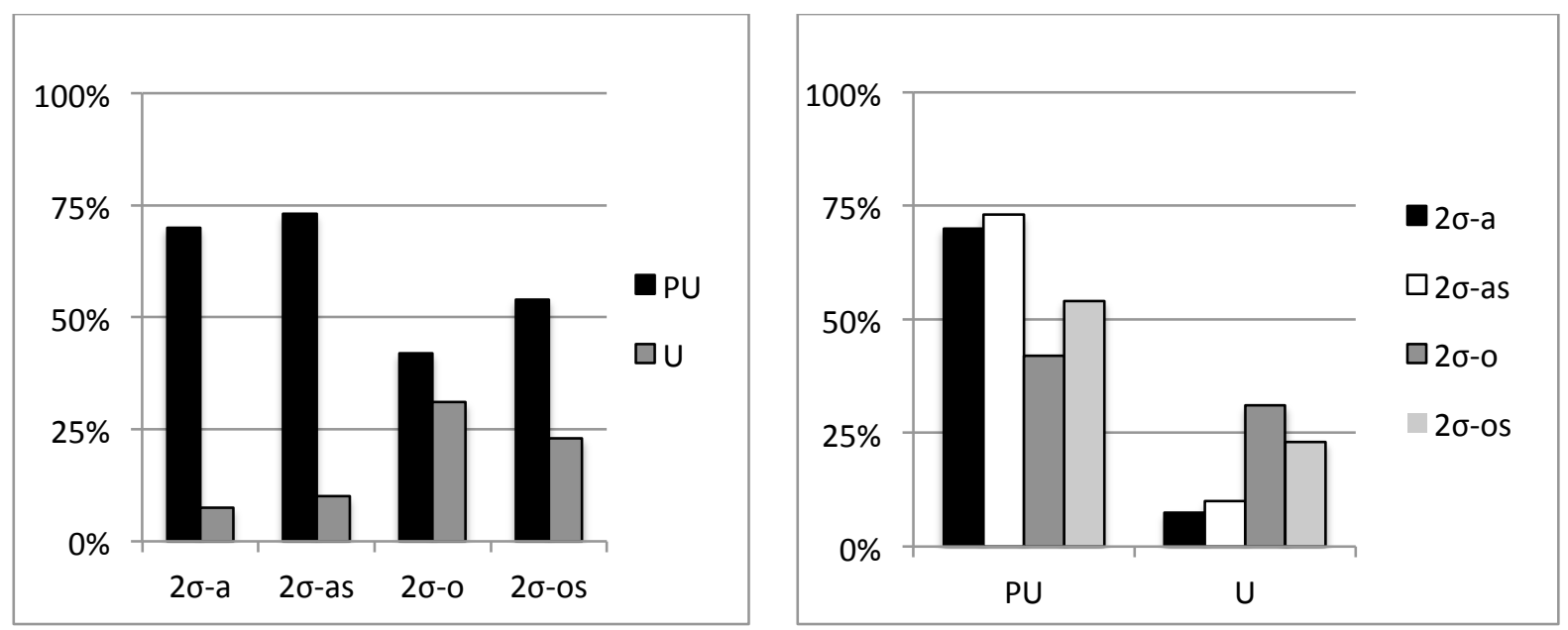

Figure 8: Percentage stress detection in $2 \sigma$ PsWs in Exp 1.

Depending on whether normality was violated (based on Shapiro-Wilk tests), a one-way Repeated Measures ANOVA with four levels was performed when the distribution of data was normal and a Non-parametric Friedman test was performed when the distribution was not normal. Both tests showed a significant effect of suffix type across stress patterns and experiments in $2 \sigma$ and $3 \sigma$ PsWs. ${ }^{11}$ More specifically, the following statistically significant ( $p$ $<0.001$ ) preference hierarchies were revealed (indicated with ' $>$ '). In cases of detection of $U$ stress by listeners $-\mathrm{o}>-\mathrm{os}>$-as, $-\mathrm{a}\left(\mathrm{N}=26\right.$, Friedman $\left.\mathrm{X}^{2}(3)=53.062, \mathrm{p}<0.001\right)$ and in cases of detection of PU stress -a, -as $>-\mathrm{os}>-\mathrm{o}\left(\mathrm{N}=26\right.$, Friedman $\left.\mathrm{X}^{2}(3)=38.976, \mathrm{p}<0.001\right)$.

In $3 \sigma$ PsWs, APU stress was preferred over PU and U stress in - $o$ and $-o s$ m-classes $(\mathrm{p}=0.000)$, while the $-a$ and $-a$ s m-classes showed a high percentage of PU stress (Figure 9). Interestingly, $U$ stress was not as marginal as one might expect since it is more likely to be associated with $3 \sigma$ nouns in $-o$ and $-o s$ than any other m-class. When looking at the preference hierarchies, the following was found. In cases of detection of U stress -os $>$-as, -a and $-\mathrm{o}>-\mathrm{a}\left(\mathrm{N}=26, \mathrm{X}^{2}(3)=19.174, \mathrm{p}<0.001\right)$; in cases of PU stress: - as $>-\mathrm{a}>-\mathrm{os}>-\mathrm{o}$ $\left(\mathrm{F}(1.847,46.177)=36.882, \mathrm{p}<0.001\right.$, partial $\eta^{2}=0.596$ with Greenhouse-Geisser correction $)$; and, finally, in cases of APU stress -os, -o $>$-as, -a $(F(3,75)=25.909, p<0.001$, partial $\left.\eta^{2}=0.509\right)$.

\footnotetext{
${ }^{11}$ For the Post hoc analysis of Friedman test and one way repeated measures ANOVA, a series of Wilcoxon signed rank tests and paired samples $t$ tests for all six combinations of suffix pairs were employed respectively with Bonferroni correction at an adjusted alpha level, $\alpha=0.05 / 6=0.0083$. In borderline cases, the HolmBonferroni version was applied since Bonferroni is known to be quite conservative.
} 


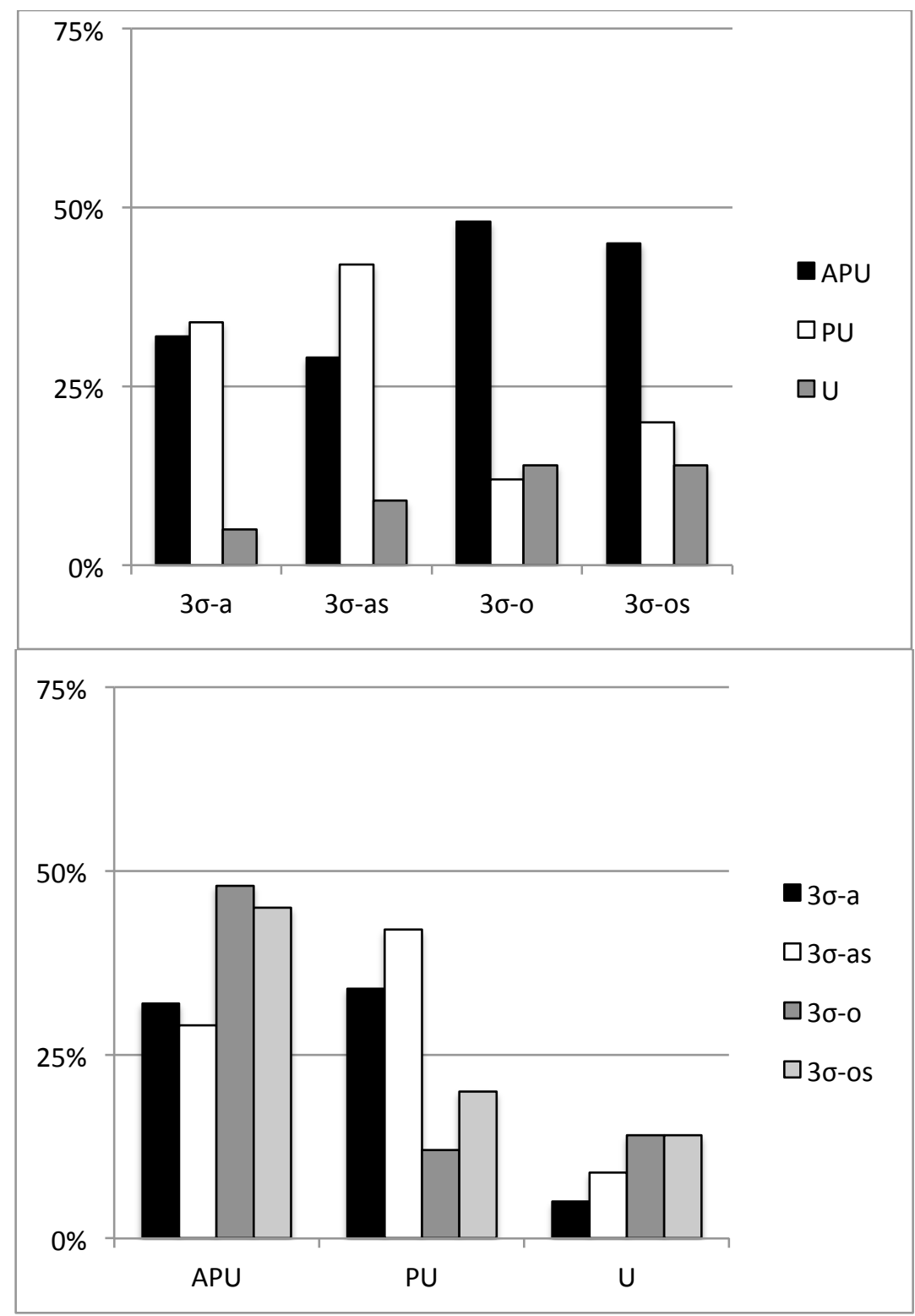

Figure 9: Percentage stress detection in $3 \sigma$ PsWs in Exp 1.

\subsubsection{Experiment 2}

The results obtained in Experiment 2 were largely very similar to the results obtained in Experiment 1. Greek listeners showed a clear preference for PU stress compared to U stress in $2 \sigma$ words (Figure 10) across morphological categories $\left(-a: \chi^{2}(1)=147.482, \mathrm{p}=0.000,-a s\right.$ : $\left.\chi^{2}(1)=288.000, \mathrm{p}=0.000,-o s: \chi^{2}(1)=121.560, \mathrm{p}=0.000\right)$ with the exception of $-o s$ whereby $\mathrm{U}$ was slightly (but not significantly $\mathrm{p}<0.5)$ preferred over PU stress $\left(-a\right.$ : $\chi^{2}(1)=147.482$, $\mathrm{p}=0.000,-$ as: $\left.\chi^{2}(1)=288.000, \mathrm{p}=0.000,-o s: \chi^{2}(1)=121.560, \mathrm{p}=0.000\right)$. 

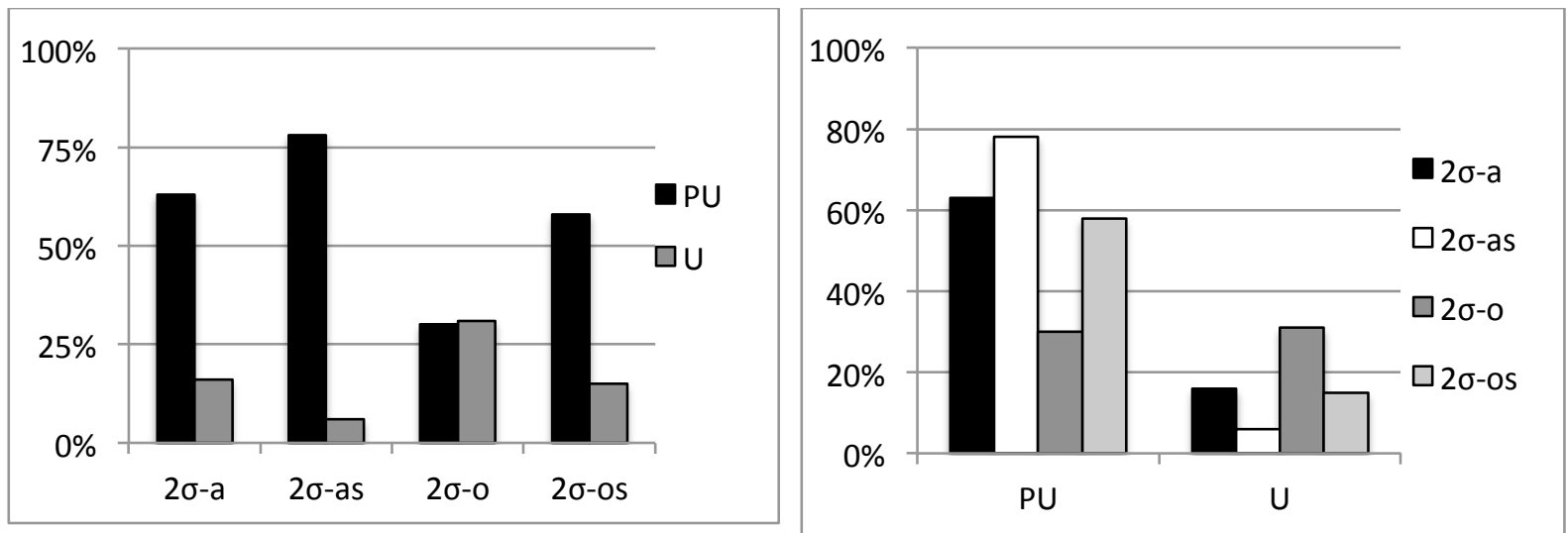

Figure 10: Percentage stress detection in $2 \sigma$ PsWs in Exp 2.

When looking at the preference hierarchies, the following pattern were found. In cases of detection of $U$ stress by listeners $-o>-o s,-a>$-as $\left(N=26\right.$, Friedman $\left.X^{2}(3)=45.518, p<0.001\right)$ and in cases of detection of PU stress -as $>-\mathrm{a}>-\mathrm{os}>-\mathrm{o}\left(\mathrm{N}=26\right.$, Friedman $\mathrm{X}^{2}(3)=49.222$, $\mathrm{p}<0.001)$.

In $3 \sigma$ PsWs, APU stress was preferred compared to PU not only in $-o$ and $-o s$ mclasses $(\mathrm{p}=0.000)$ as it was the case in Experiment 1 , but also in the $-a$ m-class. It competes, however, with PU stress in the $-a s$ class $(\mathrm{p}=0.067)$ (see Figure 11). When looking at the preference hierarchies, the following was found. In cases of detection of $U$ stress $-0,-a>-o s$, -as $\left(N=26\right.$, Friedman $\left.X^{2}(3)=27.642, p<0.001\right)$; in cases of PU stress -as $>-a>-o s,-o(N=26$, Friedman $\left.\mathrm{X}^{2}(3)=51.781, \mathrm{p}<0.001\right)$; and, finally, in cases of APU stress $-\mathrm{os}>-\mathrm{o}>-$ as, $-\mathrm{a}(\mathrm{F}(3$, $75)=37.439, \mathrm{p}<0.001$, partial $\eta^{2}=0.6$ ).

The results of both experiments therefore showed that (a) PsWs with the suffixes -o/-os are more likely to be associated with APU stress; (b) PsWs with the suffixes $-a /$-as are more likely to be associated with PU stress (but note that according to the results of Experiment 2 APU stress is a fairly common choice too); and (c) $\mathbf{U}$ stress shows a strong preference for PsWs of the $-o$ class and a moderate preference for PsWs of the -os class.

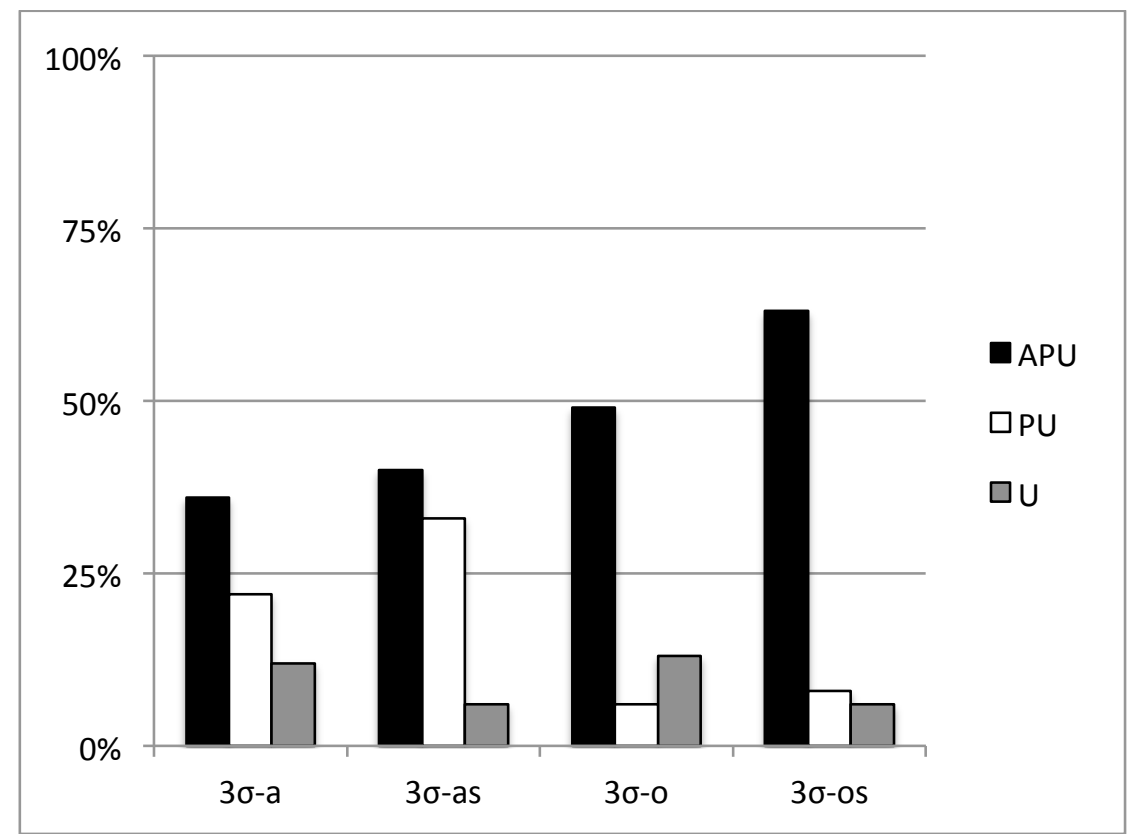




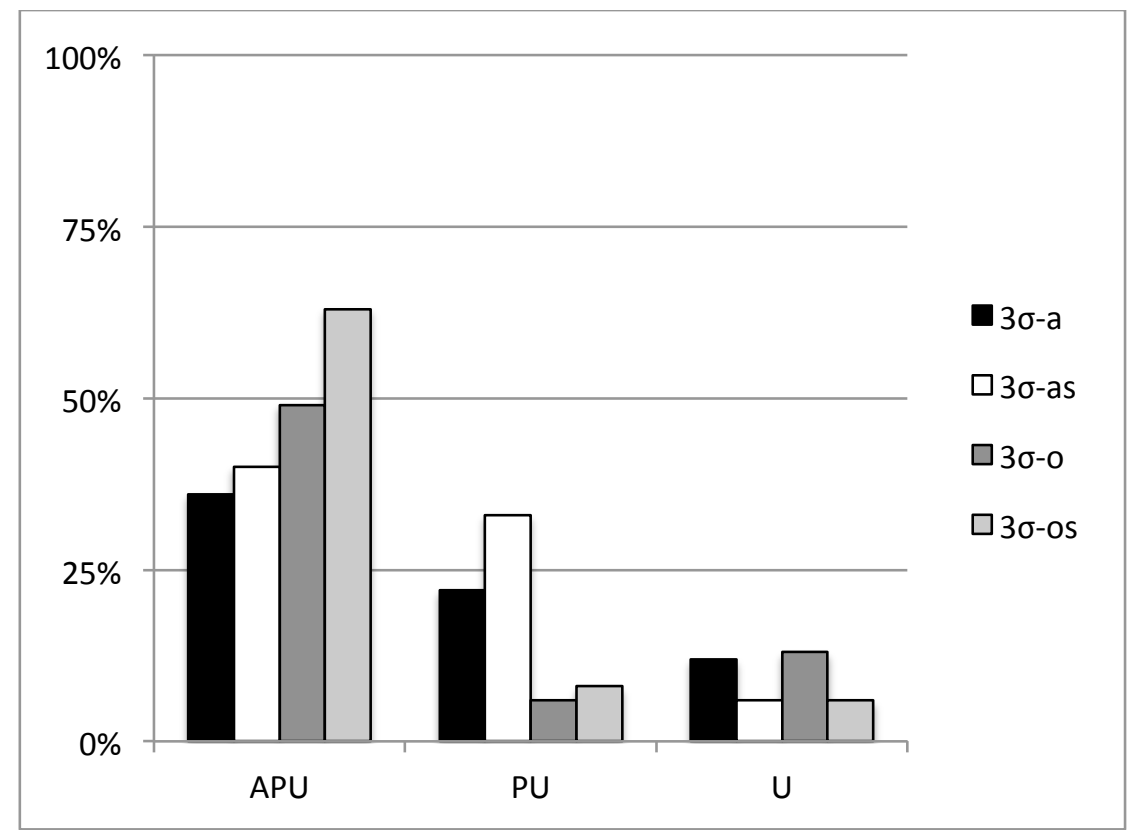

Figure 11: Percentage stress detection in $3 \sigma$ PsWs in Exp 2.

\section{Interpretation of results}

Speakers of lexical stress systems are assumed to be better qualified in perceiving stress contrasts compared to speakers of other stress systems because they have learned from infancy the specifics of the system they acquire. Our results also showed that when the acoustic cues related to stress prominence are neutralized, Greek listeners can still make judgments about the detection of prominence at high rates. Greek listeners were not only found to be stress biased but also to intuitively relate certain stress patterns with specific mclasses; a consistent finding across experiments is that PU and APU stress were closely related to $-a s$ and $-a$ m-classes, whereas $U$ stress was more favored in $-o$ and $-o s$ m-classes than any other class, suggesting that listeners do not favor a single stress pattern nor do they blindly apply the predictable by rule APU stress (i.e., the phonological default); listeners exploit all three patterns permitted by their language, albeit not evenly.

That being said, both experiments confirm beyond any doubt that the phonological default APU stress is alive and kicking, at least in certain m-classes. APU stress was the most favored choice in -o/-os $\mathrm{m}$-classes, and was chosen quite frequently by listeners in $-a /$-as $\mathrm{m}$ classes. The frequent occurrence of APU stress in our data together with its consistent affiliation with specific m-classes confirms that APU stress is not an empirically ungrounded phonological construct but instead holds an important role in Greek listeners' grammars.

Listeners' inherent encoding mechanism is only partly activated; PU stress was also a frequent stress choice, especially with specific m-classes. This means that listeners rely on underlying metrical representations when performing a stress detection task, an assumption which is further substantiated from the consistent, although quite infrequent compared to APU and PU, occurrence of $U$ stress in our data. Taken together, the results seem to suggest that Greek listeners activate underlying (i.e., PU and $U$ ) stress more frequently in specific morphological environments. It remains to be seen whether the distribution of stress patterns across m-classes reflects lexical frequency effects, a question addressed in the following section. 


\section{Stress and the Lexicon}

In order to examine whether and to what extent the Greek listeners' stress biases reflect frequency effects we compared our findings with the stress patterns reported for Greek mclasses in $2 \sigma$ and $3 \sigma$ words by Apostolouda (2012) who culled a corpus of 4.260 nouns $^{12}$ from the Anastassiadis-Symeonidis' (2002) On-line Reverse Dictionary. ${ }^{13}$

According to Apostolouda (2012), and contrary to our findings, $2 \sigma$ words in -as favor U stress over PU stress and $3 \sigma$ words in $-a$ favor PU over APU stress (Figures 12-13). ${ }^{14}$ In line with our findings, on the other hand, Apostolouda (2012) reports that U stress is the second most preferred choice in the corpus in $3 \sigma$ nouns in -os and generally exhibits elevated percentages in nouns in -o/-os compared to other m-classes. The wavering between APU and PU stress in $3 \sigma$ nouns in -as and the strong preference for APU stress in -o/-os nouns also reported in Apostolouda (2012) seems consistent with the results of our perception experiments.

It therefore seems that, if lexical frequency plays a role, this is more conspicuous in PsWs in -o/-os compared to PsWs in -a/-as (for example, $2 \sigma$ PsWs in -as do not favor U stress according to Greek listeners' judgments in either experiments). This conclusion is further supported by the fact that nouns with the theme vowel -o- are more archaic and mostly of Ancient Greek stock, whereas nouns with the theme vowel -a- represent more productive and dynamically expanded m-classes in Modern Greek (Anastassiadis 2012). In other words, the synchronically active $-a /$-as nouns set less stringent conditions on stress assignment and, we believe, reveal the productive state of affairs, i.e. by showing that the

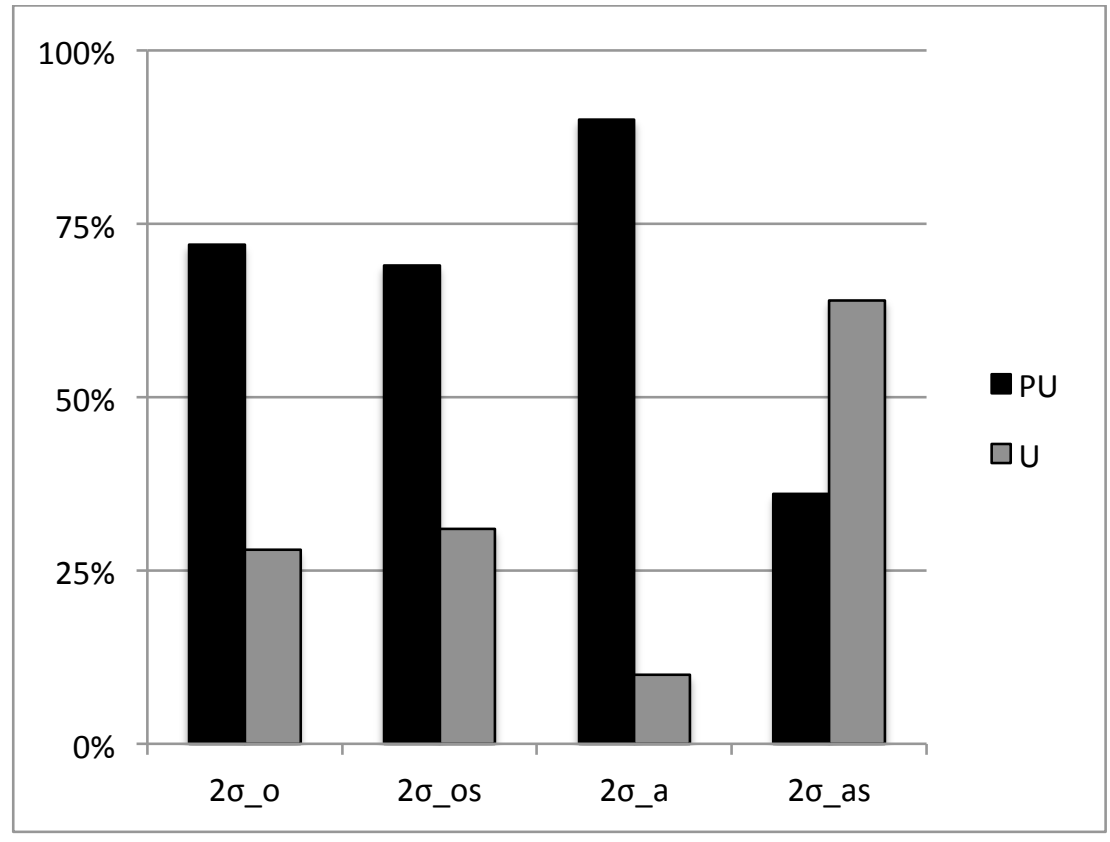

\footnotetext{
12 Apostolouda (2012) excluded from the corpus compound words, words with (transparent/non-transparent) derivational morphology, dialectal or literary words, double spelling words and words with two stress patterns (e.g., émetos emetós 'vomit').

${ }_{13}$ Available at www.greek-language.gr/greekLang/modern_greek/tools/lexica/reverse/.

${ }^{14}$ See Apostolouda et al. (2011) and Apostolouda (2012) for a detailed interpretation of the stress patterns found in the corpus.
} 
Figure 12: Percentage stress occurrence in $2 \sigma$ nouns in the Lexicon (Apostolouda 2012: 5051). ${ }^{15}$

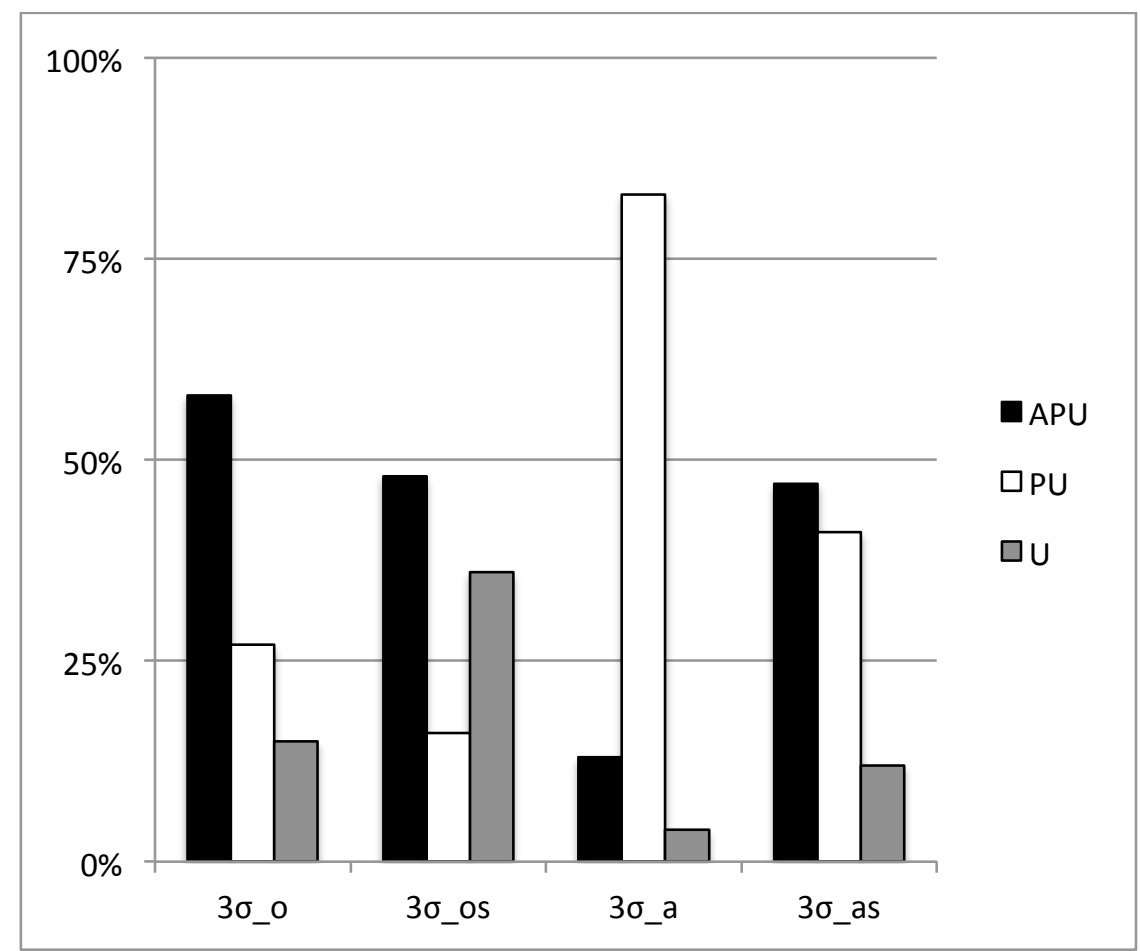

Figure 13: Percentage stress occurrence in $3 \sigma$ nouns in the Lexicon (Apostolouda 2012: 5051). ${ }^{16}$

preferred metrical preferences are APU and PU stress (i.e., binary trochees amended with the possibility for final syllable extrametricality). ${ }^{17}$

Furthermore, we believe that static/unproductive m-classes are associated with grammars that reflect more faithfully the frequency effects of the Lexicon. The low percentage of marked stress patterns (i.e., $\mathrm{U}$ stress) ${ }^{18}$ in productive m-classes (i.e., $-a /-a s$ ), however, indicates that lexical statistics are filtered by constraints that ban out marked patterns as the most/second most favored even when they prevail in the Lexicon. The fact that Greek listeners apply phonological-grounding by adjusting their outputs towards a less marked option, in terms of foot structure, leads us to conclude that they are not 'blind frequency matchers' (e.g., Frazier 1995; Fodor 1998; Zuraw 2007; Becker et al. 2011). ${ }^{19}$

15 PU vs. U: $-o: \chi^{2}(1)=35.766, \mathrm{p}=0.000 ;-o s: \chi^{2}(1)=61.213, \mathrm{p}=0.000 ;-a: \chi^{2}(1)=330.880, \mathrm{p}=0.000 ;-a s$ : $\chi^{2}(1)=5.880, \mathrm{p}=0.015$.

${ }_{16}$ (a) APU vs. PU: $-o: \chi^{2}(1)=42.853, \mathrm{p}=0.000 ;-\mathrm{os}: \chi^{2}(1)=37.751, \mathrm{p}=0.000 ;-a: \chi^{2}(1)=285.902, \mathrm{p}=0.000 ;-a s$ : $\chi^{2}(1)=.847, \mathrm{p}=.357$; (b) PU vs. U: $-o: \chi^{2}(1)=12.571, \mathrm{p}=0.000 ;-o s: \chi^{2}(1)=18.256, \mathrm{p}=0.000 ;-a: \chi^{2}(1)=393.751$, $\mathrm{p}=0.000 ;-$ as: $\chi^{2}(1)=29.369, \mathrm{p}=0.000 ;$ (c) APU vs. U: $-o: \chi^{2}(1)=94.815, \mathrm{p}=0.000 ;-o s: \chi^{2}(1)=4.000, \mathrm{p}=.046 ;-a$ : $\chi^{2}(1)=23.253, \mathrm{p}=0.000 ;-a s: \chi^{2}(1)=39.035, \mathrm{p}=0.001$.

${ }^{17} \mathrm{We}$ wish to thank an anonymous reviewer for suggesting this perspective of interpretation of the results.

${ }^{18}$ Final stress is taken to be marked because it originates either from an iamb (i.e., a marked foot type) or from a unary/degenerate trochaic foot.

${ }^{19}$ Apostolouda et al. (2011) and Apostolouda (2012) report similar findings from a production experiment. 


\section{Theoretical implications}

In this section we explore the theoretical implications of this study for (a) morphological analyses of nouns in Greek (especially with regards to the theme vowel) and (b) phonological analyses of stress that use probabilistic models to account for variation. We begin with the claim that theme vowels, commonly assumed to lack syntactic features, serve as indexes that encapsulate information on specific stress preference hierarchies. We then integrate our results into a formal analysis of stress by constructing frequency-oriented stress grammars of Greek.

\subsection{Implications for morphological analyses of Greek nouns}

According to current DM analyses (e.g., Halle \& Marantz 1993; Embick \& Noyer 2007 among others) roots are born category-free but are assigned a specific category when they merge in the syntax with functional heads (e.g., v, n, a for verbal, nominal and adjectival categories, respectively). With respect to Greek, there is also a wellformedness condition according to which at the level of morphosyntax all category functional heads require a theme position, (7) (see also Oltra-Massuet \& Arregi 2005 for Spanish). The theme vowel (THV) functions as a class marker and is necessitated by phonological wellformedness conditions (Oltra-Massuet \& Arregi 2005) that mainly require a vocalic element to link the stem and the inflection. The tree in (8) depicts the described state of affairs for the nouns anOropos 'manNOM.SG' and Aalasa 'sea-NOM.SG'.

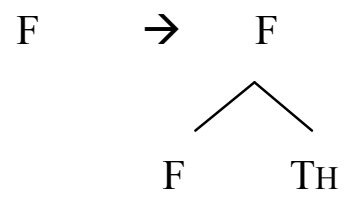

(8)

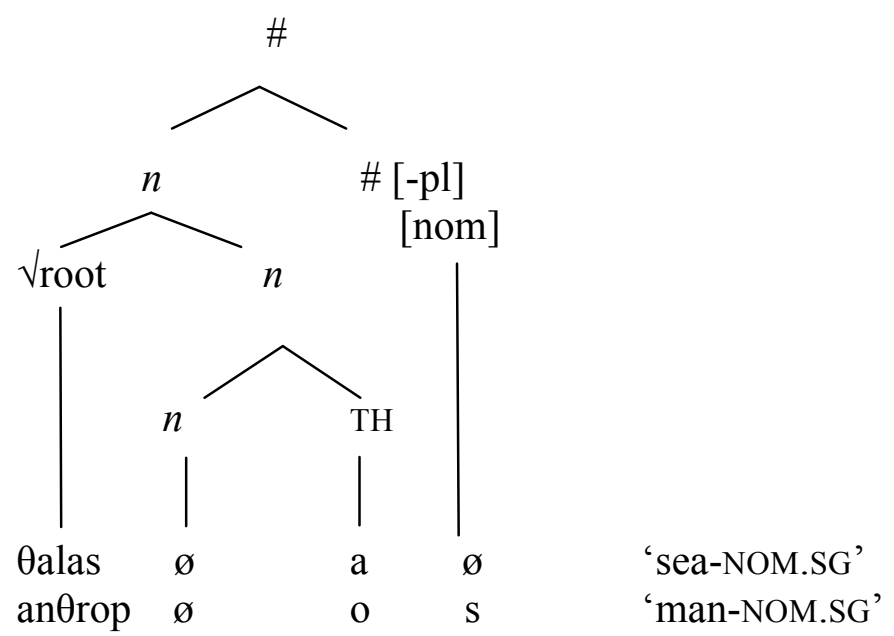

In this article, we go one step further and propose that the THV carries information on stress, specifically it serves as an index for the stress preference patterns stated in (9) (see also Section 7.2. for a formal account in terms of stochastic grammars) by helping the listener determine the hierarchical order among the three available patterns (APU, PU, U). 
(9) a. THV-a is more likely to be associated with PU or APU stress as a first stress choice.

b. THV-o is more likely to be associated with APU stress as a first stress choice.

c. THV-o is more likely than $\mathrm{ThV}-\mathrm{a}$ to be associated with $\mathrm{U}$ stress.

\subsection{Implications for phonological analyses of Greek stress}

All three available stress patterns surfaced in Greek listeners' answers but differed in terms of attested hierarchies between and within m-classes. If the default is interpreted as the preferred pattern, then we must assert that different default(s) correspond to different m-classes; APU stress is the default in nouns with the THV-o, whereas both PU and APU stress represent the default (with somewhat different likelihoods) in nouns with the THV-a. Under a representational approach to lexical stress on the other hand, (i.e. an approach that supports the existence of an underlying metrical structure in terms of accents, feet, brackets etc. and posits that the default stands for the 'elsewhere' pattern that takes over when underlying information on stress is missing), our findings could be seen to suggest that PU stress is the productive pattern of the underlying stress encoding mechanism since it primarily targets one position, namely the stem-final syllable (i.e., the juncture of morphemes). Experimental research can therefore contribute to the construction of formal analysis irrespective of the theoretical stance one adopts.

In the remaining of this section we illustrate how our results can be exploited in theoretical analyses of lexical stress via the construction of probabilistic grammars. These grammars aim at modeling the quantitative aspects of variation as these have been shaped on the basis of our listeners' judgments. To do so, we use the framework of Stochastic OT grammars originally proposed by Boersma $(1997,1998)$ and further developed by Boersma \& Hayes (2001). This model is chosen because it is accompanied by a learning theory, the Gradual Learning Algorithm (GLA), which allows us testing whether the set of our grammars' constraints are able to yield stress patterns of variation in probabilities that are close to the input (in this case, experimental) frequencies.

In Stochastic OT, constraints have numerical values (ranking values) along a numbered scale. Constraints that occupy a high number in this scale are ranked higher than those that are placed lower in the same scale. Each time a grammar evaluates a candidate set, the values are converted to a corresponding ranking. The ranking is 'fixed' when the constraints are distant enough. However, when two constraints have close or near-identical numerical values, their ranking can be reversed yielding free variation. This is because, before the numerical values are transformed into a ranking, each constraint is perturbed by adding a different positive or negative number, taken from a normal distribution with a mean of zero. This stochastic element of the theory is called noisy evaluation.

Stochastic OT can yield probability distributions that are skewed in favor of one or the other phonological pattern. To account for the distribution of Greek stress, we propose the following set of constraints (drawn from Steriade 2008):

(10) a. L-STRESS: Every syllable that is initial in a word is stressed.

b. L-STRESS-o: Every syllable that is initial in a word with the THV-o is stressed.

c. R-STRESS: Every syllable that is final in a word is stressed.

d. R-STRESS-o: Every syllable that is final in a word with the THV-o is stressed.

e. NONFIN: No stress on the final syllable.

f. *LAPSE: No two unstressed syllables $\sigma \sigma$ in a row. 
These constraints, appropriately ranked, yield the attested stress patterns. The generated grammars for each experiment are taken to be affiliated to THVs that have been argued to serve as indexes for stress. In order to capture the somewhat fossilized persistence of nouns with THV-o on APU stress and their higher chance for U stress, we introduce two parochial constraints in the set, namely $(10 \mathrm{~b}, \mathrm{~d})$.

GLA was fed with the constraint set and the candidate pairs of the tableaux in (11) and (12), for Experiment 1 and Experiment 2, respectively. Next to violation marks (indicated with numbers), we also inserted the raw numbers of the listeners' answers for each noun type (depending on size and $\mathrm{THV}$ ):

\begin{tabular}{|c|c|c|c|c|c|c|c|c|}
\hline \multicolumn{3}{|c|}{ (11) Experiment 1} & R-STRESS & R-STRESS-O & L-STRESS & L-STRESS-O & NONFIN & *LAPSE \\
\hline \multirow[t]{2}{*}{$2 \sigma-a$} & $\mathrm{PU}$ & 706 & 1 & & & & & \\
\hline & $\mathrm{U}$ & 86 & & & 1 & & 1 & \\
\hline \multirow[t]{2}{*}{$2 \sigma-0$} & $\rightarrow \mathrm{PU}$ & 470 & 1 & 1 & & & & \\
\hline & $\mathrm{U}$ & 266 & & 1 & 1 & & 1 & \\
\hline \multirow[t]{3}{*}{$3 \sigma-a$} & APU & 311 & 1 & & & & & 1 \\
\hline & $\varpi \mathrm{PU}$ & 382 & 1 & & 1 & & & \\
\hline & $\mathrm{U}$ & 69 & & & 1 & & 1 & 1 \\
\hline \multirow[t]{3}{*}{$3 \sigma-0$} & APU & 484 & 1 & 1 & & & & 1 \\
\hline & PU & 168 & 1 & 1 & 1 & 1 & & \\
\hline & $\mathrm{U}$ & 144 & & & 1 & 1 & 1 & 1 \\
\hline
\end{tabular}

\begin{tabular}{|c|c|c|c|c|c|c|c|c|}
\hline \multicolumn{3}{|c|}{ (12) Experiment 2} & R-STRESS & R-STRESS-O & L-STRESS & L-STRESS-O & NonFIN & *LAPSE \\
\hline \multirow[t]{2}{*}{$2 \sigma-a$} & $\mathrm{PU}$ & 690 & 1 & & & & & \\
\hline & $\mathrm{U}$ & 109 & & & 1 & & 1 & \\
\hline \multirow[t]{2}{*}{$2 \sigma-0$} & $\approx \mathrm{PU}$ & 428 & 1 & 1 & & & & \\
\hline & $\mathrm{U}$ & 227 & & 1 & 1 & & 1 & \\
\hline \multirow[t]{3}{*}{$3 \sigma-a$} & APU & 385 & 1 & & & & & 1 \\
\hline & PU & 277 & 1 & & 1 & & & \\
\hline & $\mathrm{U}$ & 91 & & & 1 & & 1 & 1 \\
\hline \multirow[t]{3}{*}{$3 \sigma-0$} & $\mathrm{APU}$ & 580 & 1 & 1 & & & & 1 \\
\hline & PU & 73 & 1 & 1 & 1 & 1 & & \\
\hline & $\mathrm{U}$ & 98 & & & 1 & 1 & 1 & 1 \\
\hline
\end{tabular}

The candidate set was submitted to 1,000,000 learning trials with an evaluation noise of 2.0 using OTSoft's implementation of GLA (version 2.3.2, Hayes et al. 2013). The algorithm assigned the ranking values in (13) to the constraint set for each experiment. The dispersion of constraints in a real-numbered scale is visualized in (14).

Experiment 1: Ranking Values

\begin{tabular}{|l|l|}
\hline L-STRESS-O & 102,629 \\
\hline NONFIN & 100,966 \\
\hline R-STRESS-o & 100,933 \\
\hline *LAPSE & 100,861 \\
\hline L-STRESS & 100,106 \\
\hline R-STRESS & 99,034 \\
\hline
\end{tabular}

Experiment 2: Ranking Values

\begin{tabular}{|l|l|}
\hline L-STRESS-o & 103,284 \\
\hline NONFIN & 100,748 \\
\hline R-STRESS-o & 100,698 \\
\hline L-STRESS & 100,473 \\
\hline *LAPSE & 100,275 \\
\hline R-STRESS & 99,252 \\
\hline
\end{tabular}


(14) a. Experiment 1

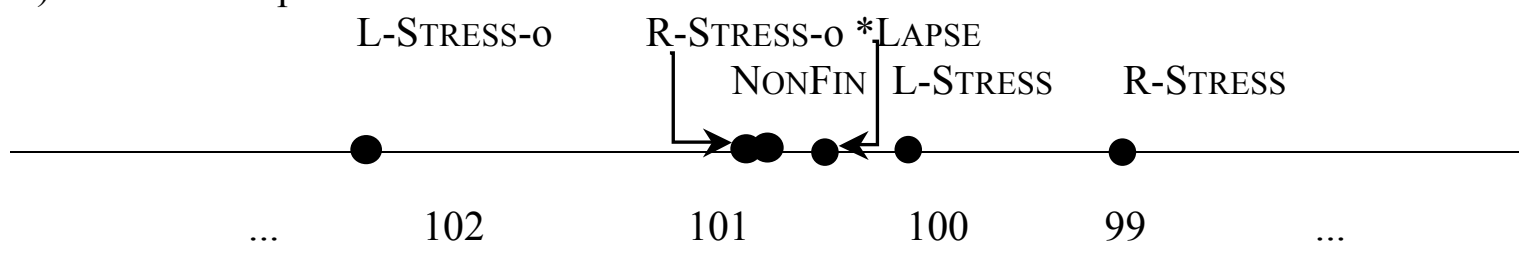

b. Experiment 2

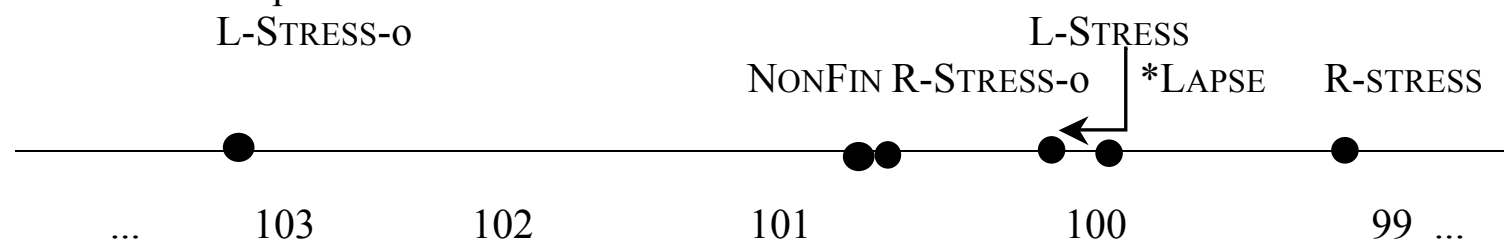

In (14a) the distance between L-STRESS-o to the other edge constraints promotes APU stress in THV-o nouns. At the same time, *LAPSE is quite close to L-STRESS to allow - through reversal of ranking - both APU and PU stress to surface in the other noun classes (i.e., THV-a nouns). Finally, the higher position of R-STRESS-o compared to R-STRESS in the scale ensures that $\mathrm{U}$ stress is more likely to arise in $o$ - rather than in $a$-nouns. Significantly, (14b) corroborates these results. It is worth mentioning that *LAPSE (which promotes PU stress) is now lower - yet very close to - L-STRESS (responsible for APU stress in $3 \sigma$ words) which subtly captures the elevated results of APU stress beyond the $o$-nouns group in Experiment 2.

A key question at this point is what the resulting grammars in (13) generate. The computation yielded the results shown in the final column of the tables in (15) and (16) for each grammar. The accuracy of predictions is extremely high; GLA worked perfectly with an average of $0,5 \%$ error per candidate for both grammars and a very good matchup of predicted to input frequencies.

(15) Experiment 1

\begin{tabular}{|l|l|l|}
\hline $\mathbf{2 \sigma}-\mathbf{a}$ & Input frequencies & Generated frequencies (learning) \\
\hline PU & 0,891 & 0,786 \\
\hline $\mathrm{U}$ & 0,109 & 0,214 \\
\hline $\mathbf{2 \sigma} \mathbf{- 0}$ & & \\
\hline $\mathrm{PU}$ & 0,639 & 0,786 \\
\hline $\mathrm{U}$ & 0,361 & 0,214 \\
\hline $\mathbf{3 \sigma - a}$ & & \\
\hline APU & 0,408 & 0,402 \\
\hline PU & 0,501 & 0,505 \\
\hline $\mathrm{U}$ & 0,091 & 0,092 \\
\hline $\mathbf{3 \sigma - 0}$ & & \\
\hline APU & 0,608 & 0,638 \\
\hline PU & 0,211 & 0,186 \\
\hline $\mathrm{U}$ & 0,181 & 0,176 \\
\hline
\end{tabular}


(16) Experiment 2

\begin{tabular}{|l|l|l|}
\hline $\mathbf{2 \sigma}-\mathbf{a}$ & Input frequencies & Generated frequencies (learning) \\
\hline PU & 0,864 & 0,775 \\
\hline$U$ & 0,136 & 0,225 \\
\hline $\mathbf{2 \sigma - 0}$ & \multicolumn{2}{|c|}{} \\
\hline PU & 0,653 & 0,775 \\
\hline$U$ & 0,347 & 0,225 \\
\hline $\mathbf{3 \sigma - a}$ & \multicolumn{2}{|l|}{} \\
\hline APU & 0,511 & 0,503 \\
\hline PU & 0,368 & 0,376 \\
\hline$U$ & 0,121 & 0,121 \\
\hline $\mathbf{3 \sigma - 0}$ & \multicolumn{2}{|l|}{} \\
\hline APU & 0,772 & 0,764 \\
\hline PU & 0,097 & 0,100 \\
\hline$U$ & 0,130 & 0,136 \\
\hline
\end{tabular}

\section{Conclusions}

The results of this study showed that Greek listeners perceived prominence in PsWs that had been manipulated so that the acoustic cues that signal stress in Greek were equated and thus were not available to them (the range of perceived prominence was $72 \%-77 \%$ across experiments and length of PsWs). The similarity of findings between Experiment 1 (all syllables stressed) and Experiment 2 (all syllables unstressed) ensures that the listeners' behavior cannot be attributed to our stress manipulation techniques. Greek listeners were found to relate certain stress judgments with specific m-classes; they showed a strong bias towards APU stress in PsWs with the suffixes $-o /-o s$ and a preference towards PU and APU stress in PsWs with the suffixes $-a /-a s$, while U stress was strongly preferred in PsWs with the suffix $-o$ and moderately preferred in PsWs of the suffix -os. This indicates that the phonological default (i.e., APU stress) is present in Greek listeners' grammars and hence empirically grounded. At the same time, our results showed that Greek listeners also favor the competitor PU stress, especially in -a/-as nouns, which suggests that a mixed APU and PU default pattern is active in the noun classes under investigation.

When comparing our findings with lexical frequencies in a Greek corpus it seems that lexical frequency has a larger effect on Greek listeners' stress preferences in PsWs in -o/-os, which static $\mathrm{m}$-classes in Greek compared to the more productive $-a /-a s$ classes. This finding combined with the fact that listeners avoided certain stress patterns (U stress) in favor of more unmarked ones (e.g., PU stress) supports a view that Greek listeners are not blind frequency matchers when performing stress detection tasks. We argue that the THV serves as an index for the stress preference patterns observed in our data; APU is more preferred in nouns with the THV-o, whereas both PU and APU are both preferred in nouns with the THVa. By using Stochastic OT grammars, it was shown that the grammars constructed for our data make extremely accurate predictions regarding the probability distributions of the Greek stress patterns and, significantly, are learnable.

This work aimed at exploring stress biases in systems with lexical stress and at gaining insights into how such biases are shaped. Future work - amended by production data - would be adopting a large-scale perspective in exploring the distribution of stress patterns across morphological classes in Greek with the ultimate goal of providing a complete picture 
of what plays a key role in shaping listeners' stress detection judgments and, ultimately, of how listeners' grammars are structured.

\section{Acknowledgements}

This research was partly supported by the 'Excellence 2011' Program [Ref.No 87883] awarded to Anthi Revithiadou and funded by the Research Committee of the Aristotle University of Thessaloniki. We wish to thank the audiences of the Ling-Lunch (University of Connecticut, 27 November 2012), University of Delaware Conference on Stress and Accent (29 November - 1 December 2012, University of Delaware) and OCP10 (16 - 19 January 2013, Boğaziçi University) for providing useful feedback. We are particularly grateful to Dimitra Ioannou for her assistance in the preparation and execution of the experiments and the codification of the data, to Sotiris Tantos for his help with the statistical analysis and to Thanassis Protopapas for his help with the use of NumTool. We would also like to thank Despina Papadopoulou, Vassilios Spyropoulos, Maria Mitsiaki, Giorgos Markopoulos for their valuable and constructive suggestions during the planning and development of this work, and of course our participants. Finally, we wish to thank three anonymous reviewers and the Editors of this volume for their constructive comments, which helped us improve the manuscript. The usual disclaimers apply.

\section{References}

Alderete, John. 1999. Morphologically governed accent in Optimality Theory. Amherst: UMass dissertation.

Alderete, John. 2001a. Morphologically governed accent in Optimality Theory. New York: Routledge.

Alderete, John. 2001b. Dominance effects as transderivational anti-faithfulness. Phonology 18. 201-253.

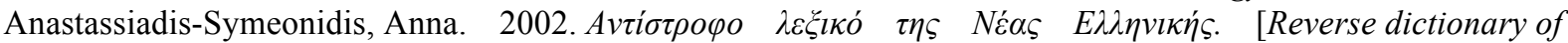
Modern Greek.] Thessaloniki: Institute of Modern Greek Studies (Manolis Triantafyllidis Foundation).

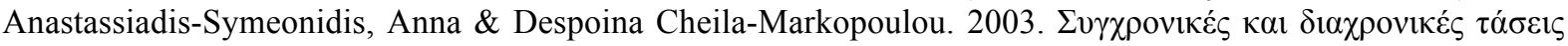

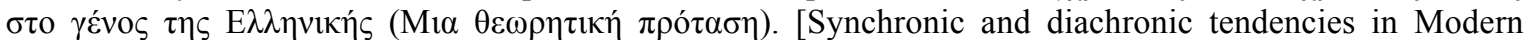
Greek gender (A theoretical proposal).] In Anna Anastassiadis-Symeonidis, Angela Ralli \& Despina CheilaMarkopoulou (eds.), To yévos [Gender], 13-56. Athens: Patakis.

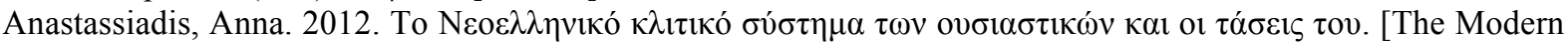
Greek nouns inflections and their trends.] In Zoe Gavriilidou, Aggeliki Efthymiou, Evaggelia Thomadaki \& Penelope Kambaki-Vougioukli (ed.), $10^{\text {th }}$ International Conference on Greek Linguistics (ICGL10), 23-40. Komitini: Democritus University of Thrace.

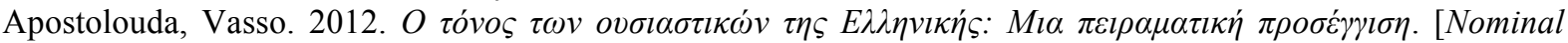
stress in Greek: An experimental approach.] Thessaloniki: AUTH MA thesis.

Apostolouda, Vasso, Despina Papadopoulou \& Anthi Revithiadou. 2011. Phonological factors outrank frequency effects. Poster presented at the 9th Old Conference in Phonology (OCP9). ZAS Berlin: Berlin.

Arvaniti, Amalia. 2002. The phonetics of stress in Greek. Journal of Greek Linguistics 1. 9-38.

Arvaniti, Amalia. 2007. Greek Phonetics: The state of the art. Journal of Greek Linguistics 8. 97-208.

Baltazani, Mary \& Sun-Ah Jun. 1999. Focus and topic intonation in Greek. $14^{\text {th }}$ International Congress of Phonetic Sciences (ICPhS XIV), 1305-1308. San Francisco.

Becker, Michael F., Nihan Ketrez \& Andrew Nevins. 2011. The surfeit of the stimulus: Analytical biases filter lexical statistics in Turkish laryngeal alternations. Language 87. 84-125.

Boersma, Paul. 1997. How we learn variation, optionality, and probability. Institute of Phonetic Sciences of the University of Amsterdam, 43-58. http://www.fon.hum.uva.nl/Proceedings/Proceedings21/CONTP21.html. (20 June 2014.)

Boersma, Paul. 1998. Functional phonology: Formalizing the interaction between articulatory and perceptual drives. The Hague: Holland Academic Graphics LOT Dissertation Series 1.

Boersma, Paul \& Bruce Hayes. 2001. Empirical tests of the Gradual Learning Algorithm. Linguistic Inquiry 32. 45-86. 
Boersma, Paul \& David Weenink. 2011. Praat: Doing phonetics by computer (Version 5.2.27). http://www.praat.org. (24 June, 2011.)

Burzio, Luigi \& Niki Tantalou. 2007. Modern Greek accent and faithfulness constraints in OT. Lingua 117. 1080-1124.

Crosswhite, Katherine, John Alderete, Tim Beasly \& Vita Markman. 2003. Morphological effects on default stress placement in Russian novel words: An experimental approach. In Gina Garding \& Mimu Tsujimura (eds.), $22^{\text {nd }}$ West Coast Conference on Formal Linguistics (WCCFL 22), 151-164. Somerville, MA: Cascadilla Press.

Dupoux, Emmanuel \& Sharon Peperkamp. 2002. Fossil markers of language development: Phonological deafnesses in adult speech processing. In Jacques Durand \& Bernard Laks (eds.), Phonetics, phonology, and cognition, 168-190. Oxford: Oxford University Press.

Dupoux, Emmanuel, Núria Sebastian-Galles, Eduardo Navarrete \& Sharon Peperkamp. 2008. Persistent stress 'deafness': The case of French learners of Spanish. Cognition 106. 682-706.

Embick, David \& Rolf Noyer. 2007. Distributed Morphology and the syntax/morphology interface. In Gillian Ramchand \& Charles Reiss (eds.), The Oxford handbook of linguistic interfaces, 289-324. Oxford: Oxford University Press.

Fainleib, Lena. 2008. Default stress in unpredictable stress languages: Evidence from Russian and Hebrew. TAU MA thesis.

Fodor, Janet D. 1998. Learning to parse? Journal of Psycholinguistic Research 27(2). 285-319.

Frazier, Lynn. 1995. Constraint satisfaction as a theory of sentence processing. Journal of Psycholinguistic Research 24. 437-468.

Halle, Morris. 1973. The accentuation of Russian words. Language 49. 312-348.

Halle, Morris. 1997. On stress and accent in Indo-European. Language 73. 275-313.

Halle, Morris \& William Idsardi J.. 1995. General properties of stress and metrical structure. In John Goldsmith, Jason Riggle \& Alan C. L. Yu (eds.), The handbook of phonological theory, 403-443. Oxford \& Cambridge, MA: Blackwell Publishers.

Halle, Morris \& Alec Marantz. 1993. Distributed Morphology and the pieces of inflection. In Kenneth Hale \& Samuel J. Keyser (eds.), The view from building 20. 111-176. Cambridge: MIT Press.

Hayes, Bruce \& Zsuzsa Londe. 2006. Stochastic phonological knowledge: The case of Hungarian vowel harmony. Phonology 23. 59-104.

Hayes, Bruce, Bruce Tesar \& $\quad$ Kie $\quad$ Zuraw. 2013. $\quad$ OTSoft 2.3.2. http://www.linguistics.ucla.edu/people/hayes/otsoft. (2 June, 2014.)

Holton, David, Peter Mackridge \& Irene Philippaki-Warburton. 1997. Greek: A comprehensive grammar of the modern language. London: Routledge.

Hulst, Harry van der. 1999. Word stress. In Harry van der Hulst (ed.), Word prosodic systems in the languages of Europe, 3-115, Berlin \& New York: Mouton de Gryuter.

Hulst, Harry van der. 2012. Deconstructing stress. Lingua 122. 1494-1521.

Idsardi, William. 1992. The computation of prosody. Cambridge, MA: MIT dissertation.

Inkelas, Sharon. 1999. Exceptional stress-attracting suffixes in Turkish: Representations vs. the Grammar. In Harry van der Hulst, René Kager \& Wim Zonneveld (eds.), The prosody-morphology interface, 134-187. Cambridge: Cambridge University Press.

Kiparsky, Paul. 1982. The lexical phonology of Vedic accent. Cambridge, MA: MIT

Kiparsky, Paul \& Morris Halle. 1977. Toward a reconstruction of the Indo-European accent. In Larry M. Hyman (ed.), Studies in stress and accent, 209-238. University of Southern California: Los Angeles.

Lavitskaya, Yulia \& Barış Kabak. 2011a. Russian accentual system revisited: Experimental and diachronic evidence. Paper presented at the $8^{\text {th }}$ Old Conference in Phonology (OCP8). Marrakesh, Casablanca.

Lavitskaya, Yulia \& Barış Kabak. 2011b. Default stress in Russian: An experimental study. Paper presented at the International Workshop on Suprasegmentals in Acquisition and Processing. University of Konstanz, Konstanz.

Lavitskaya, Yulia \& Barış Kabak. 2013. Phonological default in a lexical stress system. Manuscript, University of Konstanz \& University of Wurzburg.

Malikouti-Drachman, Angeliki \& Gaberell Drachman. 1989. Stress in Greek. Studies in Greek linguistics 1989, 127-143. University of Thessaloniki.

Melvold, Janis Leanne. 1990. Structure and stress in the phonology of Russian. Cambridge, MA: MIT dissertation.

Nikolaeva, Tatiana. 1971. Mesto udareniia i foneticheskii sostav slova (rasstanovka udareniia v neizvestnykh slovakh inostrannogo proizkhozhdeniia). In Fedot P. Filin (ed.), Fonetika. Fonologiia. Grammatika. K semidesiatiletiiu A.A. Reformatskogo [Phonetics. Phonology. Grammar. For the 70th Birthday of A.A. Reformatskii]. Moscow: Nauka. 
Nikolou, Kalomoira, Anthi Revithiadou \& Despina Papadopoulou. 2012. Exceptional stress patterns in the absence of morphological conditioning. In Zoe Gavriilidou, Aggeliki Efthymiou, Evaggelia Thomadaki \& Penelope Kambaki-Vougioukli (eds.), $10^{\text {th }}$ International Conference on Greek Linguistics (ICGL10), 472479. Komitini: Democritus University of Thrace.

Oltra-Massuet, Isabel \& Carlos Arregi. 2005. Stress-by-structure in Spanish. Linguistic Inquiry 36. $43-84$.

Peperkamp, Sharon. 2004. Lexical exceptions in stress systems: Arguments from early language acquisition and adult speech perception. Language 80. 98-126.

Peperkamp, Sharon \& Emmanuel Dupoux. 2002. A typological study of stress 'deafness'. In Carlos Gussenhoven \& Natasha Warner (eds.), Laboratory phonology 7, 203-240. Berlin \& New York: Mouton de Gryuter.

Protopapas, Athanassios, Svetlana Gerakaki \& Stella Alexandri. 2006. Lexical and default stress assignment in reading Greek. Journal of Research in Reading 29(4). 418-432.

Protopapas, Athanassios, Marina Tzakosta, Aimilios Chalamandaris, \& Pirros Tsiakoulis. 2010. IPLR: An online resource for Greek word-level and sublexical information. Language Resources and Evaluation. http://link.springer.com/article/10.1007\%2Fs10579-010-9130-z.

Ralli, Angela. 2002. The role of morphology in gender determination: Evidence from Modern Greek. Linguistics 40. 519-551.

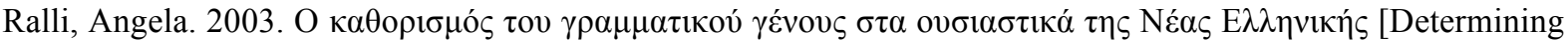
grammatical gender in Modern Greek nouns]. In Anna Anastassiadis-Symeonidis, Angela Ralli \& Despina Cheila-Markopoulou (eds.), To yévoৎ [Gender], 57-99. Athens: Patakis.

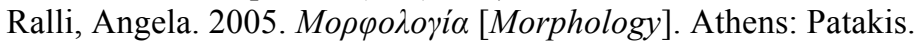

Ralli, Angela \& Loudovikos Touratzidis. 1992. A computational treatment of stress in Greek inflected forms. Language and Speech 35. 435-453.

Revithiadou, Anthi. 1999. Headmost accent wins: Head dominance and ideal prosodic form in lexical accent systems. The Hague: Holland Academic Graphics LOT Dissertation Series 15.

Revithiadou, Anthi. 2007. Colored Turbid accents and Containment: A case study from lexical stress. In Sylvia Blaho, Patrick Bye \& Martin Krämer (eds.), Freedom of Analysis?, 149-174. Berlin \& New York: Mouton de Gruyter.

Revithiadou, Anthi, Dimitra Ioannou, Maria Chatzinikolaou \& Katerina Aivazoglou. 2012. Constructing pseudowords for experimental research: A case study. Poster presented at the $4^{\text {th }}$ Conference on Language Disorders in Greek. TEI of Patras, Patras.

Steriade, Donca. 2008. Lecture notes for the class Language and its structure I: Phonology. Fall 2008, MIT.

Topintzi, Nina \& Evia Kainada. 2012. Acronyms and the placement of default stress in Greek. In Zoe Gavriilidou, Aggeliki Efthymiou, Evaggelia Thomadaki \& Penelope Kambaki-Vougioukli (eds.), $10^{\text {th }}$ International Conference on Greek Linguistics (ICGL10), 559-570. Komitini: Democritus University of Thrace.

Varlokosta, Spyridoula. 2011. The role of morphology in grammatical gender assignment: A psycholinguistic study in Greek. In Alexandra Galani, Glyn Hicks \& George Tsoulas (eds.), Morphology and its interfaces, 49-76. Amsterdam: John Benjamin.

Zuraw, Kie. 2000. Patterned exceptions in phonology. UCLA dissertation.

Zuraw, Kie. 2007. The role of phonetic knowledge in phonological patterning: Corpus and survey evidence from Tagalog. Language 83. 277-316. 


\section{Appendix: Pseudowords used in the two experiments}

\section{i. Pseudowords}

\begin{tabular}{|c|c|c|c|c|c|}
\hline & Fem -a & Masc -as & Fem/Neut $-i$ & Neut -o & Masc -os \\
\hline $2 \sigma$ & 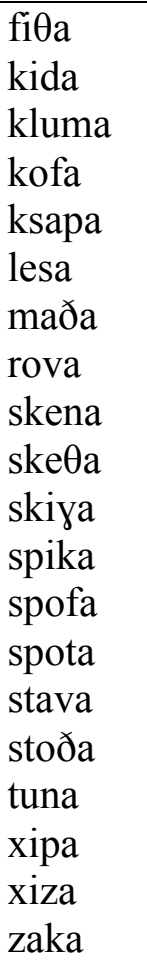 & 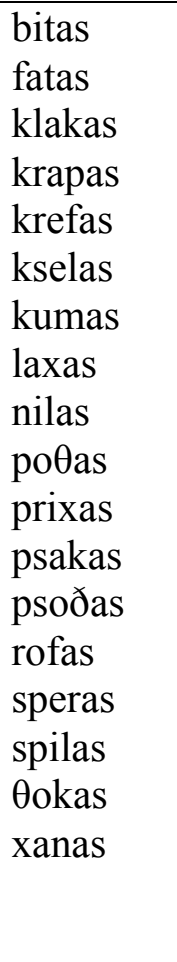 & 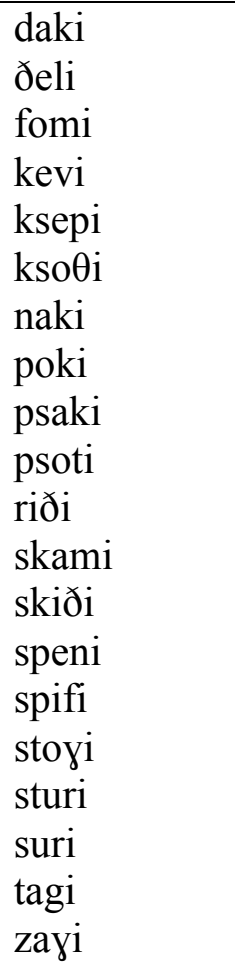 & $\begin{array}{l}\text { ðalo } \\
\text { kafo } \\
\text { kleto } \\
\text { kloto } \\
\text { peyo } \\
\text { peӨo } \\
\text { skaðo } \\
\text { skiðo } \\
\text { skoðo } \\
\text { skofo } \\
\text { skuto } \\
\text { spaðo } \\
\text { spolo } \\
\text { tamo } \\
\text { vero } \\
\text { vralo } \\
\text { xato } \\
\text { xeto } \\
\text { zano } \\
\text { zoto }\end{array}$ & 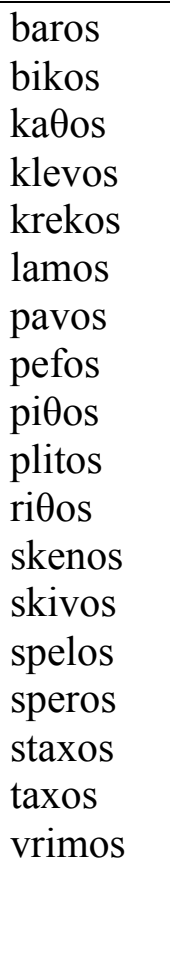 \\
\hline $3 \sigma$ & $\begin{array}{l}\text { diraza } \\
\text { fizera } \\
\text { yalefa } \\
\text { kasova } \\
\text { kraðila } \\
\text { krixena } \\
\text { letoma } \\
\text { paloða } \\
\text { proteða } \\
\text { skayin } \\
\text { skaliӨa } \\
\text { skinaka } \\
\text { skiveta } \\
\text { spaseta } \\
\text { speleta } \\
\text { statifa } \\
\text { vayoka } \\
\text { zakena } \\
\text { zavota } \\
\text { zikara }\end{array}$ & $\begin{array}{l}\text { yotiras } \\
\text { kaleyas } \\
\text { kareva } \\
\text { klapikas } \\
\text { kliseras } \\
\text { kraðenas } \\
\text { kroliðas } \\
\text { lavenas } \\
\text { paneðas } \\
\text { paroðas } \\
\text { piloðas } \\
\text { pinazas } \\
\text { praminas } \\
\text { skolinas } \\
\text { skolisas } \\
\text { spatilas } \\
\text { travonas } \\
\text { trivetas } \\
\text { vaturas }\end{array}$ & $\begin{array}{l}\text { ðipavi } \\
\text { kefoti } \\
\text { kinofi } \\
\text { klatavi } \\
\text { koveti } \\
\text { lifori } \\
\text { penami } \\
\text { retili } \\
\text { saxeni } \\
\text { skapevi } \\
\text { skeyani } \\
\text { skireni } \\
\text { spafeti } \\
\text { spiteli } \\
\text { stiferi } \\
\text { stixevi } \\
\text { stolevi } \\
\text { tapoyi } \\
\text { treðani } \\
\text { zifoni }\end{array}$ & $\begin{array}{l}\text { fasero } \\
\text { kayero } \\
\text { kelaso } \\
\text { klipano } \\
\text { lapa } \theta \text { o } \\
\text { lotazo } \\
\text { pareðo } \\
\text { peleto } \\
\text { raveno } \\
\text { ritevo } \\
\text { skayano } \\
\text { skefeto } \\
\text { skelito } \\
\text { skipero } \\
\text { spasano } \\
\text { spifono } \\
\text { spimaxo } \\
\text { stivoro } \\
\text { stixero } \\
\text { tazelo }\end{array}$ & 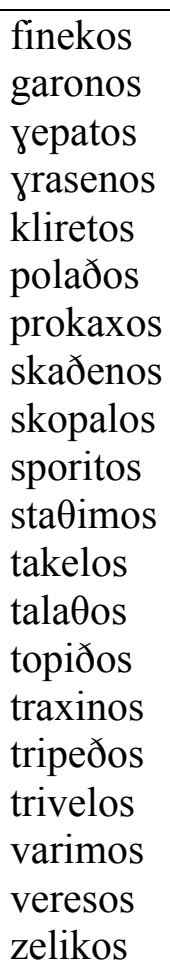 \\
\hline
\end{tabular}




\section{ii. Fillers}

\begin{tabular}{|c|c|c|c|c|c|}
\hline & Fem -a & Masc -as & Fem/Neut $-i$ & Neut -o & Masc -os \\
\hline $2 \sigma$ & $\begin{array}{l}\text { maðá } \\
\text { kída } \\
\text { klumá } \\
\text { kófa } \\
\text { skéna } \\
\text { spofá }\end{array}$ & $\begin{array}{l}\text { nilás } \\
\text { kréfas } \\
\text { psákas } \\
\text { ksélas } \\
\text { sperás } \\
\text { Ookás }\end{array}$ & $\begin{array}{l}\text { ðéli } \\
\text { ksépi } \\
\text { náki } \\
\text { riðí } \\
\text { skamí } \\
\text { skiðí }\end{array}$ & $\begin{array}{l}\text { ðálo } \\
\text { skáðo } \\
\text { klotó } \\
\text { skófo } \\
\text { vraló } \\
\text { xáto } \\
\text { zanó } \\
\text { veró }\end{array}$ & 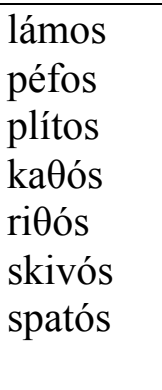 \\
\hline $3 \sigma$ & $\begin{array}{l}\text { protéða } \\
\text { yálefa } \\
\text { kráðila } \\
\text { skinaká } \\
\text { spaséta } \\
\text { zikará }\end{array}$ & $\begin{array}{l}\text { paroðás } \\
\text { pilóðas } \\
\text { yótiras } \\
\text { klapikás } \\
\text { kliséras } \\
\text { spátilas }\end{array}$ & $\begin{array}{l}\text { lífori } \\
\text { kéfoti } \\
\text { klataví } \\
\text { retilí } \\
\text { skapévi } \\
\text { spáfeti } \\
\text { tapóyi }\end{array}$ & $\begin{array}{l}\text { fásero } \\
\text { lotazó } \\
\text { lipá日o } \\
\text { klipanó } \\
\text { skelitó } \\
\text { skipéro } \\
\text { stíxero }\end{array}$ & $\begin{array}{l}\text { polaðós } \\
\text { prokaxós } \\
\text { gáronos } \\
\text { klíretos } \\
\text { tripéðos } \\
\text { verésos }\end{array}$ \\
\hline
\end{tabular}

